どが 1 種類の速度てう配, 流速についてのあのであっ た. 本研究では速度こう配, 流速をそれぞれ 4 種類に 変化させて測定を行った. その結果，以下の事が判明 した.

（1）発生した直線せ九断流は二次元と見なしう る.

（2）同一のせん断格子によって発生したせん断流 については $G, T_{u},-\overline{u v} / U_{c}^{2}, R_{u v}$ は $U_{c} K$ よらず一定である. また $G$ は $x / h$ にあよらず 一定である.

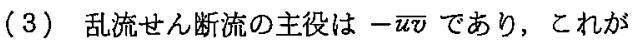
$G$ を保ち $L_{x}, T_{u}$ を決定している. これらの 量はいずれす一訬ととすに増加する.

（4）乱流せん断流の乱机は，周期成分を潜在した ランダム変動であり，通常の乱れに比へるる， より多くのエネルギを主流加ら得ている.

\section{参考文献}

1) OWEN, P.R. \& ZIENkIEwICZ, H.K.: The production of uniform shear flow in a wind tunnel, J. Fluid Mech., Vol. 2, (1957), pp. 521-531.

2) Livesey, J.L. \& Turner, J.T.: The generation of symmetrical duct velocity profiles of high uniform shear, J. Fluid Mech., Vol. 20, No. 2, (1964), pp. 201-208.

3) Rose, W. G.: Results of an attempt to generate a homogeneous turbulent shear flow, J. Fluid Mech., Vol. 25, No. 1, (1966), pp. 97-120.

4) Champagne, F.H., Harris, V.G. \& Corrsin, S.: Experiments on nearly homogeneous turbulent shear flow, J. Fluid Mech., Vol. 41, No. 1, (1970), pp. 81-139.

5) Rose, W.G.: Interaction of grid turbulence with a uniform mean shear, J. Fluid Mech., Vol. 44, No. 4, (1970), pp. 767-779.

6) Schuichting. H. : Boundary Layer Theory, 6 th ed. McGraw-Hill., (1968). p. 531-538

\title{
質量が変化する弾性飛しょう体の運動方程式* \\ The Equations of Motion of an Elastic \\ Launch Vehicle with Varying Mass
}

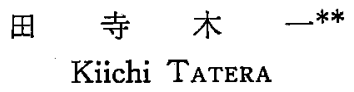

\begin{abstract}
General three dimensional dynamic equations of motion for a launch vehicle with varying mass are derived, having effects of airframe bending, propellant sloshing, propellant flow and engine swiveling into account. Further, as* suming the propellant flow, lateral bending shapes and some small quantities concerning a vehicle, derived equations are applied to a moderate or large launch vehicle with multiple gimbaledengines, and the effects of aforementioned phenomena on the dynamic equations are shown in detail.

In this paper, the effect of propellant flow are considered as reaction forces of propellant to the airframe, and using the theory of continuum mechanics the time rate of change of integrals of some quantities are expressed by the net rate at which the quantities are being transfered out of the system.
\end{abstract}

\section{1. 緒 言}

質量が変化しつつあるロケットについて, 重心位置

* 昭和 48 年 3 月 30 日原稿受理

** 航空字宙技術研究所
変化, 機体の横曲げ, 横スロッシングおよびエンジン 運動を考慮して，3次元的な一般動力学運動方程式を 導いた.さらに，ロケット内部の流体運動の仮定，合 理的な assumed モードの使用および若千の適当な微 小量の設定を行ない，得られた運動方程式をジンバル 式液体ロケットに適用して，運動方程式におよぽす上 記諸現象の影響，ならび諸現象間の相互影響を䛨し く示した。

質量変化を伴う系の運動は，多くの人によって論ぜ られ(例えば文献 1)〜6))，それらの取扱いと表現式 は多様である.乙れらの結果は飛しょう体の運動力学

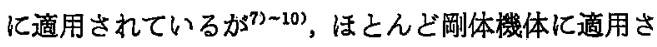
れ，上記諸現象を取扱った報告は LESTER and COLLINS ${ }^{93}$ に見られるだけである，そてでは，変分原理に 基ついた Lagrange 形式の運動方程式より，ピッチ面 内の運動のみを求めているが，全運動エネルギーには 内部液体の流れを無視し片手落ちとなっている．また 機体軸江垂直方向の重心移動の無視およびエンジン除 外の曲げ assumed モードの使用などのため，必要以 上に式が複雔となっている，こてでは，内部流体の流 れの影響は機体におよ注す反力として考えて，部分的 に連続体力学の場の量の取扱い方法を導入して, 系か 
らの流出量で式を表わし，取扱い易い運動方程式を得 た.

\section{2. 座標系と質量素片の運動方程式}

運動座標系として直交機体軸系を用い，機体が弾性 変形をうけないと仮想したときの機体に固定し，とれ を $x y z$ 系（第 1 図）とする. ロケット内の任意の質 量素片を $d m, \bar{a}$ を $d m$ の慣性空間加速度（量記号 上の棒楾はベクトル量を表わす)， $\tilde{T}$ を応力テンソル

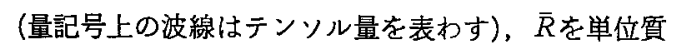
量あたりの体積力， $d \tau$ を $d m$ の占める体積素片とす ると， $d m$ の運動方程式は固体部および流体部につい $\tau$, 次式で表わされる ${ }^{12(i)),}$

$$
\bar{a} d m=\nabla \cdot \tilde{T} d \tau+\bar{R} d m
$$

ととに， $\nabla$ は発散演算子である. また重心に対するモ ーメントの釣合いから次式を得る12,(i)（第 1 困).

$$
\begin{aligned}
& \left(\bar{r}-\bar{r}_{c}\right) \times \bar{a} d m=-\nabla \cdot\left\{\tilde{T} \times\left(\bar{r}-\bar{r}_{c}\right)\right\} d \tau \\
& \quad+\left(\bar{r}-\bar{r}_{c}\right) \times \bar{R} d m
\end{aligned}
$$

いま，口ケットを第 2 図の如く，時刻 $t$ において体積 領域 $\tau$ を占める固体部之， $\tau^{\prime}$ を占める流体部 (固体推 進薬は固体部亡するのが適当かも知れないが，燃陞殷 のあのは燃焼面が移動するので，乙こでは後の式の簡 単化の都合上流体部に入れる）に分け，前者を团む表 面を $\sigma$, 後者のをれを $\sigma^{\prime}$ とすると,

$$
\sigma=\sigma_{s}+\sigma_{s f}, \quad \sigma^{\prime}=\sigma_{s s}+\sum_{n} \sigma_{e n}
$$

ここに， $\sigma_{s s}$ は固体と流体部との接する面， $\sigma_{e n}$ は第

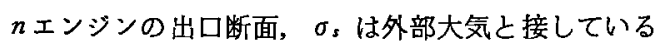
固体表面とする. ロケットの運動は各瞬間において， 限定された面 $\sigma_{s}$ と $\Sigma \sigma_{\text {en }}$ によって囲まれた空間内の 物質の運動を知ることであり，流動し流出する流体が

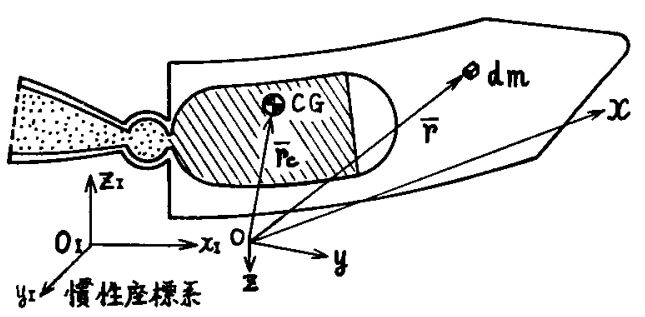

$$
\text { 第 } 1 \text { 図座 標 桑 }
$$

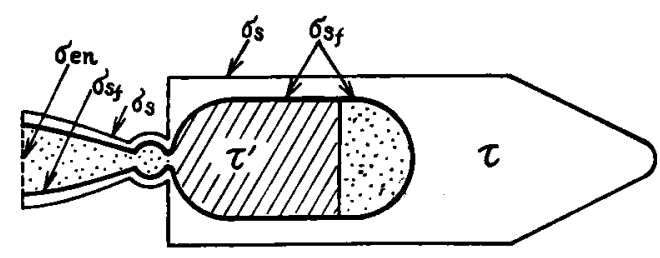

第2図 ロケットの物質領域
機体に作用する力は， $\sigma_{s f}$ を通して作用する表面力と 考えるととが出来，固体部はこの流体による反力をう ける.

\section{3. 基 礎 式}

3.1 重心の運動 任意の座標原点の運動とそのま わりの回軽運動式を導入するかわりに，以下では紙数 の関係上一般に用いられている重心に関係する式を導 入する.（1)をそれぞれ固体部と流体部について積分 する. とのさい発散定理（付録 1) を用いて, $\nabla \cdot \widetilde{T}$ の体積皘分を面積積分で表わすと，

$$
\begin{aligned}
& \int_{\tau} \bar{a} d m=\int_{\sigma_{s}} \bar{n}_{\tau} \cdot \tilde{T} d s+\int_{\sigma_{s f}} \bar{n}_{\tau} \cdot \tilde{T} d s+\int_{\tau} \bar{R} d m \\
& \int_{\tau^{\prime}} \bar{a} d m=\int_{\sigma_{s f}} \bar{n}_{\tau^{\prime}} \cdot \tilde{T} d s+\sum_{n} \int_{\sigma_{\theta n}} \bar{n}_{t^{\prime}} \cdot \tilde{T} d s \\
& \quad+\int_{\tau^{\prime}} \bar{R} d m
\end{aligned}
$$

ここに， $\bar{n}_{\tau} ， \bar{n}_{\tau}^{\prime}$ はそれぞれ $\tau ， \tau^{\prime}$ 部を囲む表面の面 積要素 $d s$ 亿垂直な外方向単位べクトルである. $\bar{n}_{\tau}$. $\tilde{T} d s ， \bar{n}_{\tau}{ }^{\prime} \cdot \tilde{T} d s$ はそれぞれ $\sigma ， \sigma^{\prime}$ のds 《作用する 表面力で，（5）の右辺の最初の積分項は符号を变える 上，流体部が固体部に执よばす力となる． $\sigma_{s f}$ 面で $\bar{n}_{\tau} \cdot \tilde{T} d s$ と $\bar{n}_{\tau}{ }^{\prime} \cdot \tilde{T} d s$ は, 同一点では大きさは同じで 逆方向であるから，(4)，(5)ょり

$$
\begin{aligned}
& \int_{\tau+\tau^{\prime}} \bar{a} d m=\bar{F} \\
& \bar{F}=\int_{\sigma_{s}} \bar{n}_{\tau} \cdot \tilde{T} d s+\sum_{n} \int_{\tau_{a n}} \bar{n}_{\tau}{ }^{\prime} \cdot \tilde{T} d s \\
& \quad+\int_{\tau+\tau^{\prime}} \bar{R} d m
\end{aligned}
$$

いま， $\bar{V}_{0}$ を原点 0 の慣性空間速度， あを機体軸系 の回転角速度， $\bar{v}_{s} ， \bar{v}_{f}$ をそれぞれ着目する固体およ び流体部の $d m$ の機体軸系に対する速度とすると, $d m$ の慣性空間速度 $\bar{V}$ は,

$$
\left.\begin{array}{ll}
\bar{V}=\bar{V}_{0}+\bar{w} \times \bar{r}+\bar{v}_{1} & \text { for } \tau \\
\bar{V}=\bar{V}_{0}+\bar{w} \times \bar{r}+\bar{v}_{s} & \text { for } \tau^{\prime}
\end{array}\right\}
$$

また $\bar{V}_{c}\left(V_{c x}, V_{c y}, V_{c x}\right)$ を重心の慣性空間速度とす ると,

$$
\bar{V}_{c}=\bar{V}_{0}+\bar{w} \times \bar{r}_{c}+\dot{\bar{r}}_{c}
$$

したがって， $\bar{V}$ を $\bar{V}_{c}$ で表わすと，

$$
\left.\begin{array}{ll}
\bar{V}=\bar{V}_{c}+\bar{w} \times\left(\bar{r}-\bar{r}_{c}\right)+\bar{v}_{s}-\dot{\bar{r}}_{c} & \text { for } \tau \\
\bar{V}=\bar{V}_{c}+\bar{w} \times\left(\bar{r}-\bar{r}_{c}\right)+\bar{v}_{f}-\dot{\bar{r}}_{c} & \text { for } \tau^{\prime}
\end{array}\right\}
$$

（·）は時間変化率を表わし, ベクトルのときは機体軸 系の成分に関して時間微分を行う。したがって 


$$
\left.\begin{array}{ll}
\bar{a}=\dot{\bar{V}}_{c}+\varpi \times \bar{V}_{c}+\overline{\bar{w}} \times\left(\bar{r}-\bar{r}_{c}\right)+\varpi \times\left(\bar{w} \times\left(\bar{r}-\bar{r}_{c}\right)\right)+2 \varpi \times\left(\bar{v}_{s}-\dot{\vec{r}}_{c}\right)+\dot{v}_{s}-\ddot{r}_{c} & \text { for } \tau \\
\bar{a}=\dot{\bar{V}}_{c}+\bar{w} \times \bar{V}_{c}+\dot{\bar{w}} \times\left(\bar{r}-\bar{r}_{c}\right)+\varpi \times\left(\varpi \times\left(\bar{r}-\bar{r}_{c}\right)\right)+2 w \times\left(\bar{v}_{f}-\dot{\bar{r}}_{c}\right)+\dot{v}_{f}-\dot{\bar{r}}_{c} & \text { for } \tau^{\prime}
\end{array}\right\}
$$

$\dot{\bar{v}}_{s}, \dot{\bar{v}}_{s}$ は機体軸系に対する加速度で，いま， $m$ を時 刻 $t$ のロケット全質量として， $\bar{r}_{c}$ 之重心の運動方程 式は,

$$
\begin{aligned}
& m \bar{r}_{c}=\int_{\tau+z^{\prime}} \bar{r} d m \\
& m\left[\dot{\bar{V}}_{c}+\bar{w} \times \bar{V}_{c}-2 \bar{w} \times \dot{\bar{r}}_{c}-\ddot{\bar{r}}_{c}\right] \\
& \quad+2 w \times\left[\int_{\tau} \bar{\nabla}_{s} d m+\int_{\tau^{\prime}} \bar{\nabla}_{f} d m\right] \\
& \quad+\int_{\tau} \dot{\bar{v}}_{s} d m+\int_{\tau^{\prime}} \dot{\bar{y}}_{f} d m=\bar{F}
\end{aligned}
$$

ここで， $m ， \bar{r}_{c}$ と乙れらの時間変化率間の関係を考え る. $d^{*} / d t$ を( ) と同一とし, (12) 亿 $d^{*} / d t$ を遂行し $\tau$,

$$
\dot{m} \bar{r}_{c}+m \dot{\bar{r}}_{c}=\frac{d^{*}}{d t} \int_{\tau+\tau^{\prime}} \bar{r} d m
$$

との右辺は $\sigma_{s}$ と $\sum_{n} \sigma_{e n}$ によって围まれた(第 2 図)， $\tau+\tau^{\prime}$ 空間内の物質に付随した嘼の，機体軸系より見 た時間変化率であるから（付 2.4）と（付 2.5)により，

$$
\begin{aligned}
& \frac{d^{*}}{d t} \int_{\tau+\tau^{\prime}} \bar{r} d m=\frac{D^{*}}{D t} \int_{\tau+\tau^{\prime}} \bar{r} d m=\int_{\tau} \bar{v}_{s} d m \\
& \quad+\int_{\tau^{\prime}} \bar{v}_{s} d m-\sum_{n} \int_{\sigma_{s n}} \rho_{s} \bar{r}\left[\left(\bar{v}_{f}-v_{s}\right) \cdot \bar{n}_{\tau^{\prime}}\right] d s
\end{aligned}
$$

$\bar{v}_{s}$ は流出面 $\sigma_{e n}$ の機体軸に相対的な速度である. し たがって，(14)，(15)加ら，

$$
\begin{aligned}
& \int_{\tau} \bar{v}_{s} d m+\int_{\tau^{\prime}} \bar{v}_{s} d m=\frac{d^{*}}{d t}\left(m \bar{r}_{c}\right) \\
& \quad+\sum \int_{\sigma_{s s}} \rho_{s} \bar{r}\left[\left(\bar{v}_{s}-\bar{v}_{s}\right) \cdot \bar{n}_{\tau^{\prime}}\right] d s
\end{aligned}
$$

同様にして，さらに(16)の $d^{*} / d t$ を遂行すると，

$$
\begin{aligned}
& \int_{\tau} \dot{v}_{s} d m+\int_{\tau^{\prime}} \bar{v}_{f} d m=\frac{d^{* 2}}{d t}\left(m \bar{r}_{c}\right) \\
& \quad+\sum_{n} \int_{\sigma_{\theta n}} \rho_{f} \bar{v}_{f}\left[\left(\bar{v}_{f}-\bar{v}_{s}\right) \cdot \bar{n}_{\tau}^{\prime}\right] d s \\
& \quad+\frac{d^{*}}{d t} \sum_{n} \int_{\sigma_{e n}} \rho_{f} \bar{r}\left[\left(\bar{v}_{f}-\bar{v}_{s}\right) \cdot \bar{n}_{\tau}^{\prime}\right] d s
\end{aligned}
$$

(16)，(17) の右辺の第 2 項は，それぞれ $\sum_{n} \sigma_{o n}$ 面か ら単位時間任流出する $\rho_{f} \vec{r} d s, \rho_{f} \bar{v}_{r} d s$ の総和で，両 式を(13) に用いて，

$$
\begin{aligned}
& m\left[\dot{\bar{V}}_{c}+\bar{w} \times \bar{V}_{c}\right]+2 \dot{m} \dot{\dot{r}_{c}}+\ddot{m}_{\bar{r}} \bar{r}_{c}+2 \dot{m} \bar{w} \times \bar{r}_{c} \\
& \quad+\frac{d^{*}}{d t} \sum_{n} \int_{\sigma_{s n}} \rho_{f} \bar{r}\left[\left(\bar{v}_{f}-\bar{v}_{s}\right) \cdot n_{\tau^{\prime}}\right] d s \\
& +2 \varpi \times \sum_{n} \int_{\sigma_{e n}} \rho_{f} \bar{r}\left[\left(\bar{v}_{f}-\bar{v}_{s}\right) \cdot \bar{n}_{\tau}{ }^{\prime}\right] d s \\
& \quad+\sum_{n} \int_{\sigma_{e n}} \rho_{f} \bar{v}_{f}\left[\left(\bar{v}_{f}-\bar{v}_{s}\right) \cdot \bar{n}_{\tau}^{\prime}\right] d s=\bar{F}
\end{aligned}
$$

上式は一般式で，(13) と(18) は全く同一式であるが， 後者は $\bar{r}_{c}$ と諸量の流出率で表わされ，系の内部物質 の相対加速度を知る必要はない，したがって解析に有 利と考えられる.

3.2 重心まわりの回転運動（2)式加ら，次の重 心まわりのモーメントの釣合い式を得る.

$$
\int_{\tau+\tau^{\prime}}\left(\bar{r}-\bar{r}_{\epsilon}\right) \times \bar{a} d m=\bar{M}
$$

$\bar{M}$ は (7) と同様に發散定理（付録 1)により次式を 得る.

$$
\begin{aligned}
\bar{M} & =\int_{\sigma_{s}}\left(\bar{r}-\bar{r}_{c}\right) \times\left(\bar{n}_{\tau} \cdot \tilde{T}\right) d s \\
& +\sum_{n} \int_{\sigma_{\varepsilon n}}\left(\bar{r}-\bar{r}_{\epsilon}\right) \times\left(\bar{n}_{\tau}{ }^{\prime} \cdot \tilde{T}\right) d s \\
& +\int_{\tau+\tau^{\prime}}\left(\bar{r}-\bar{r}_{c}\right) \times \bar{R} d m
\end{aligned}
$$

(11)を(19)に代入し， $\tilde{I}$ を $x y z$ 系に関する重心まわ りの慣性モーメントテンソル（付録 3）とすると，

$$
\begin{aligned}
& \tilde{I} \cdot \dot{\bar{w}}+\bar{w} \times(\bar{I} \cdot \bar{w})+2\left[\int_{\tau}\left(\bar{r}-\bar{r}_{c}\right) \times\left(\bar{w} \times \bar{v}_{s}\right) d m\right. \\
& \left.+\int_{\tau^{\prime}}\left(\bar{r}-\bar{r}_{c}\right) \times\left(\bar{w} \times \bar{v}_{s}\right) d m\right]+\int_{\tau}\left(\bar{r}-\bar{r}_{c}\right) \\
& \quad \times \dot{\bar{v}}_{s} d m+\int_{\tau^{\prime}}\left(\bar{r}-\bar{r}_{c}\right) \times \dot{v}_{s} d m=\bar{M}
\end{aligned}
$$

ここで，(21)式の変形を考える，まず（付 2.4）と （付 2・5)を用いて $d^{*} / d t(\tilde{I} \cdot \varpi)$ は，

$$
\begin{aligned}
& \frac{d^{*}}{d t}(\tilde{I} \cdot \bar{w})=\frac{d^{*}}{d t}\left[\int_{\tau}\left(\bar{r}-\bar{r}_{c}\right) \times\left(\bar{w} \times\left(\bar{r}-\bar{r}_{c}\right)\right) d m\right. \\
& \left.\quad+\int_{\tau^{\prime}}\left(\bar{r}-\bar{r}_{c}\right) \times\left(\bar{w} \times\left(\bar{r}-\bar{r}_{c}\right)\right) d m\right]=\bar{I} \cdot \dot{\bar{w}} \\
& \quad+\int_{\tau}\left[_{\tau_{s}} \times\left(\bar{w} \times\left(\bar{r}-\bar{r}_{c}\right)\right)+\left(\bar{r}-\bar{r}_{c}\right)\right. \\
& \left.\quad \times\left(\bar{w} \times \bar{v}_{s}\right)\right] d m+\int_{\tau^{\prime}}\left[\bar{v}_{f} \times\left(\bar{w} \times\left(\bar{r}-\bar{r}_{c}\right)\right)\right. \\
& \left.\quad+\left(\bar{r}-\bar{r}_{c}\right) \times\left(\bar{w} \times \bar{v}_{f}\right)\right] d m-\Sigma \int_{\sigma_{e}} \rho_{f}\left(\bar{r}-\bar{r}_{c}\right) \\
& \quad \times\left(\bar{w} \times\left(\bar{r}-\bar{r}_{c}\right)\right) \cdot\left[\left(\bar{v}_{f}-\bar{v}_{s}\right) \cdot \bar{n}_{r}^{\prime}\right] d s
\end{aligned}
$$

(22) の最後の式の第 2 項之第 3 項の積分式を, ベクト 儿積の関係式, $\bar{A} \times(\bar{B} \times \bar{C})+\bar{C} \times(\bar{B} \times \bar{A})=2 \bar{C} \times(\bar{B} \times$ $\bar{A})-\bar{B} \times(\bar{C} \times \bar{A})$ を用いて变形する.つぎに， $\bar{L}$ なる 量すなわち機体軸系加ら見た角運動量を導入する.

$$
\bar{L}=\int_{\tau} \bar{r} \times \bar{v}, d m+\int_{\tau^{\prime}} \bar{r} \times \dot{v}_{f} d m
$$

さらに， $\bar{L}$ から（付 2-4)，(付 2-5）を用いて，

$$
\frac{d^{*} \bar{L}}{d t}=\int_{\tau} \bar{r} \times \dot{v}, d m+\int_{\tau^{\prime}} r \times \dot{v}_{s} d m
$$




$$
-\sum_{n} \int_{\sigma_{e n}} \rho_{f} \bar{r} \times \bar{v}_{f}\left[\left(\bar{v}_{f}-\bar{v}_{s}\right) \cdot \bar{n}_{\tau}{ }^{\prime}\right] d s
$$

が得られる，(22)を変形した式と，(15)，(17)，(23) (24)等を用いて，結局(21)式として次式を得る。

$$
\begin{aligned}
& d^{*} / d t(\tilde{I} \cdot \bar{w})+\bar{w} \times(\tilde{I} \cdot \bar{w})+d^{*} / d t(\bar{L})+\bar{w} \times \bar{L} \\
& -\bar{r}_{c} \times d^{* 2} / d t\left(m \bar{r}_{c}\right)-\bar{w} \times\left[\bar{r}_{c} \times d^{*} / d t\left(m \bar{r}_{c}\right)\right] \\
& -\bar{r}_{c} \times \frac{d^{*}}{d t} \sum_{n} \int_{\sigma_{e n}} \rho_{f} \bar{r}\left[\left(\bar{v}_{f}-\bar{v}_{s}\right) \cdot \bar{n}_{\tau}^{\prime}\right] d s \\
& -\bar{w} \times\left\{\bar{r}_{c} \times \sum_{n} \int_{\sigma_{e n}} \rho_{f} \bar{r} \cdot\left[\left(\bar{v}_{f}-\bar{v}_{s}\right) \cdot \bar{n}_{\tau}^{\prime}\right] d s\right\} \\
& +\sum_{n} \int_{\sigma_{e n}} \rho_{f}\left(\bar{r}-\bar{r}_{c}\right) \times \bar{v}_{f}\left[\left(\bar{v}_{f}-\bar{v}_{s}\right) \cdot \bar{n}_{\tau}^{\prime}\right] d s \\
& +\sum_{n} \int_{\sigma_{e n}} \rho_{f}\left(\bar{r}-\bar{r}_{c}\right) \times\left(\bar{w} \times\left(\bar{r}-\bar{r}_{c}\right)\right)\left[\left(\bar{v}_{f}\right.\right. \\
& \left.\left.-\bar{v}_{s}\right) \cdot \bar{n}^{\prime}\right] d s=\bar{M}
\end{aligned}
$$

上式の左辺の最初の 2 項が通常のオイラーの式に対応 するが, 玄は０とは限らない、ジェット・ダンピング は種々の定義が見られるが12.45, 左辺の最後の項が 多くの著者によりジェット・ダシピングといわれてい $ろ^{5)}$ （21)と(25)は同一内容の式で，後者は $\tilde{I}, \bar{r}_{c}$ 以 外に $\bar{I}$. と流出率を知る必要がある. しかし，一般に 系からの諸量の流出率は容易に分かる場合が多く，ま た $\bar{L}$ は流体の流れが軸方向で軸対称と仮定出来ると きは0となるので，非常に簡笚な式となる，との報告 の完成段階で最近, transport rule による運動方程式 が示された ${ }^{11)}$. 検討の結果によると(18)，(25)式はそ の結果に合致している。

3.3 流体運動 タンク内の液体推進桠および燃焼 室内のガスの運動は，機体の弾性変形之の相互作用に より，非常に複雑である．この運動は初期および境界 条件，連続の式，エネルギー式，燃焼特性その他の constitutive equations を用いて，解くことが出来る かす知れないが，ここでは，スロッシング効果は縦ス ロッシングを無視し，横スロッシングに対して質量一 スプリングーダシュポットの等価力学系で表わし（第 3 図 $)^{14)}$, 液体および燃焼 ガスの排出流運動は, 仮定 を設けてこれを用いる。

3.4 曲げ変形運動 刻々に質量が変化し，しかも ジンパル・エンジンのような非保存力による運動を伴

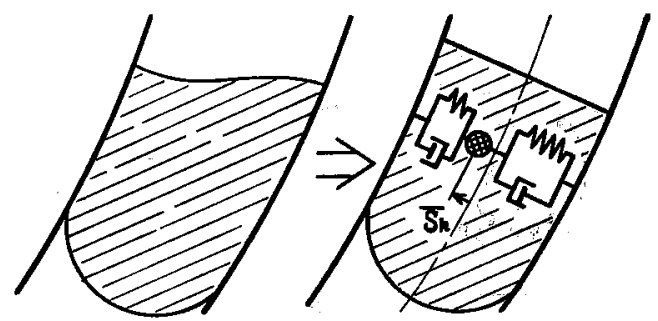

第3図 横スロッシングの等価力学的モテル
う全系の固有振動モードは，通常の意味に扣いては存 在しない. したがって何らかの仮想的な制限下にお ける機体モード形を用いて曲げ变形を表わす。この assumed モード形の選び方によって，スロッシング質 量およびェンジンの慣性力と曲げ振動のカップリング の度合か左右され，かつ同一精度で曲げ変位を表わし 得るモード形のとるべき項数が異なる。ここではカッ プリング項が少なくて，しかあスロッシング運動およ びェンジン運動の個々の物理的な意味が明瞭に保持さ れているように，流体はスロッシング質量む含めて frozen し，エンジンは初期設定位置で固定された仮 想的な束縛下に招ける固有振動モードを用いる。

この第 $\nu$ 次固有掁動の円振動数を $w_{\nu}$ ，一般兵量を $m_{\nu}$, 減衰比を $\zeta_{\nu}$ ，モード形を $\bar{\phi}_{\nu}(\bar{r}, t)$ として, 曲げ 変位 $\bar{u}(\bar{r}, t) は$, 次式で表わされると仮定する.

$$
\bar{u}(\bar{r}, t)=\sum_{\nu} \xi_{\nu}(t) \bar{\phi}_{\nu}(\bar{r}, t)
$$

$\xi_{\nu}$ は $\bar{\phi}_{\nu}$ の一般座標である.

弾性振動方程式は，例えば BISPLINGHOFF の教科 書 $^{(2)}$ に従えば，付録 4、の（付 4.1）式で表わされ る、いまこれを適用するにあたって，スロッシング質 量の動遥，流体の機体に対する相対的な流れおよびエ ンジンのふれ運動等の有効力を外力の如く考える必要 加ある.（付 4・1）に減衰項を追加し

$$
\begin{aligned}
& m_{\nu} z w_{\nu}^{2} \xi_{\nu}=-\int_{\tau+\tau^{\prime}} \bar{a}_{a} \cdot \bar{\phi}_{\nu} d m+Q_{e \nu}-2 m_{\nu} \zeta_{\nu} w_{\nu} \dot{\xi}_{\nu} \\
& \quad+Q . \\
& m_{\nu}=\int_{\tau+\tau^{\prime}} \bar{\phi}_{\nu} \cdot \bar{\phi}_{\nu} d m
\end{aligned}
$$

ここに， $\bar{a}_{a}$ はモード計算の際に，仮定した束縛条件 下における加速度，Q。vは上記の有効力を外力上考元 た一般力， $Q$ 、はロケットの外力による一般力である.

3.5 エンジンの運動 第 $n$ エンジンのジンバル点 $G_{n}$ から $d m$ への位置ベクトルを $\bar{r}^{\prime}$ として, $G_{n} ま$ わりのモーメントの釣合い式は，(2)から

$$
\int_{\tau\left(E_{n}\right)+\tau^{\prime}\left(E_{n}\right)} \bar{r}^{\prime} \times \bar{a} d m=\bar{M}_{e s}
$$

ここに, $\tau\left(E_{n}\right), \tau^{\prime}\left(E_{n}\right)$ はそれぞれ第 $n$ エンジンの固 体部と流体部で， $\bar{M}_{\text {en }}$ エエンジンに㗢くモーメントで ある.

$$
\begin{aligned}
& d m \text { の } \bar{a} \text { は，第 } 4 \text { 図の記号を用いて，(11)より， } \\
& \bar{a}=\dot{\bar{V}}_{c}+\varpi \times \bar{V}_{c}+\dot{\bar{w}} \times\left(\bar{r}_{g n}+\bar{r}^{\prime}-\bar{r}_{c}\right)+\varpi \\
& \times\left\{\bar{w} \times\left(\bar{r}_{a \pi}+\bar{r}^{\prime}-\bar{r}_{c}\right)\right\}+2 \bar{w} \times\left(\bar{v},-\dot{\bar{r}}_{c}\right) \\
& +\dot{\bar{v}}_{s} \rightarrow \ddot{\bar{r}}_{e} \quad \text { for } \tau\left(E_{n}\right) \\
& \bar{a}=\dot{\bar{V}}_{c}+\bar{w} \times \bar{V}_{a}+\dot{\bar{w}} \times\left(\bar{r}_{a n}+\bar{r}^{\prime}-\bar{r}_{c}\right)+\bar{w} \\
& \left.\times\left\{\varpi \times \bar{r}_{g^{n}}+\bar{r}^{\prime}-\bar{r}_{c}\right)\right\}+2 \bar{w} \times\left(\bar{v}_{f}-\dot{\bar{r}}_{c}\right)+\bar{v}_{f}-\ddot{\bar{r}}_{c} \\
& \text { for } \tau^{\prime}\left(E_{n}\right)
\end{aligned}
$$

第 $n$ エンジンのガスも含めた全䢙量を $m_{e n}, G_{n}$ の慣 


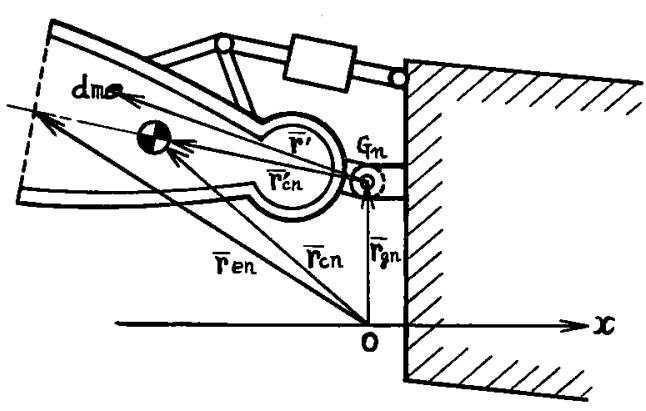

第 4 図 第 $n$ エンジンの座標

性空間加速度を $\bar{a}_{\theta n}, I_{e n}$ を $x y z$ 系化関する $G_{n}$ ま わりのエンジンの慣性モーメントテンソルとして, (29)より,

$$
\begin{aligned}
& \tilde{I}_{e n} \cdot \dot{\bar{w}}+\bar{w} \times\left(\tilde{I}_{e n} \cdot \bar{w}\right)+m_{e n} \bar{r}_{c n}^{\prime} \times \bar{a}_{\ell n} \\
& +2\left[\int_{\tau\left(E_{n}\right)} \bar{r}^{\prime} \times\left\{\bar{w} \times\left(\bar{v}_{s}-\dot{\bar{r}}_{e n}\right)\right\} d m\right. \\
& \left.+\int_{\tau^{\prime}\left(E_{n}\right)} \bar{r}^{\prime} \times\left\{\bar{w} \times\left(\bar{\nu}_{f}-\dot{\bar{r}}_{o n}\right)\right\} d m\right] \\
& +\int_{\tau\left(E_{n}\right)} \bar{r}^{\prime} \times\left(\dot{\bar{v}}_{s}-\ddot{\bar{r}}_{\theta n}\right) d m+\int_{\tau^{\prime}\left(E_{n}\right)} \bar{r}^{\prime} \\
& \times\left(\dot{\bar{v}}_{f}-\ddot{\bar{r}}_{\theta n}\right) d m=\bar{M}_{e n}
\end{aligned}
$$

(21)から(25)を導いたときと同様にして，エンジンへ の流入面 $\sigma_{e i n}$ を考虑して， $G_{n}$ まわりの回転運動方 程式は,

$$
\begin{aligned}
& d^{*} / d t\left(\tilde{I}_{e n} \cdot \bar{w}\right)+\bar{w} \times\left(\tilde{I}_{e n} \cdot \bar{w}\right)+m_{e n} \bar{r}_{e n}^{\prime} \times \bar{a}_{g n} \\
& \quad+d^{*} / d t\left(\bar{L}_{e n}\right)+\bar{w} \times \bar{L}_{e n}+\int_{\sigma_{e n}+\sigma_{e l n}} \rho_{f} \bar{r}^{\prime} \\
& \quad \times\left(\bar{w} \times \bar{r}^{\prime}\right)\left[\left(\bar{v}_{f}-\bar{v}_{s}\right) \cdot \bar{n}_{\tau}^{\prime}\right] d s \\
& \quad+\int_{\sigma_{e n}+\sigma_{e i n}} \rho_{f} \bar{r}^{\prime} \times\left(\bar{v}_{f}-r_{\theta n}\right)\left[\left(\bar{v}_{f}-\bar{v}_{s}\right) \cdot \bar{n}_{\tau^{\prime}}\right] d s \\
& =\bar{M}_{e n} \\
& \bar{L}_{e n}=\int_{\tau\left(E_{n}\right)} \bar{r}^{\prime} \times\left(\bar{v}_{s}-\bar{r}_{\theta n}\right) d m+\int_{\tau^{\prime}\left(E_{n}\right)} \bar{r}^{\prime} \\
& \quad \times\left(\bar{v}_{f}-\overline{\bar{r}}_{\theta n}\right) d m
\end{aligned}
$$

となる。

\section{4. 基礎式の夜体ロケットへの適用}

3.では一般的な式を導いた，以下で，これを中型な いし大型衛星打上げ用液体ロケットに適用する。

4.1 前提条件 (i ) 機体は機軸を含むピッチおよ びョ一面に対して対称とし，燃烧段のタンクは単一 （複数への搪張は困難でない）とする， $x$ 凁は中心軸 で機首方向に， $y ， z$ 軸はそれぞれ，ピッチ，ヨ一韩 により，原点 $O$ はジンバル点を通る $x$ 軸に垂直な面内 による.

（ii）エンジンは複数でジンバル式とし，おのおの のエンジンの構造, 燃焼等の特性は同一とし，かつ岡
体とし，軸対称で，初期 canted angle は無視する. エンジンの配置はピッチ扰びョ一面に対称で，個々 のエンジンへの推進薬流量（一 $\dot{m}_{n}$ (正)) は一定亡す る.ここで， $\dot{m}_{n}$ は巣なる記号で，時間微分を意味し ない.

(iii） 3.4 の曲げ固有振動モード形は，ロケットを 自由一自由の棒状構造と考え，ピッチ面およびョ一面 の $\bar{k} \phi_{p v}(x, t), \quad \bar{j} \phi_{y y^{\prime}},(x, t)$ で表わされるとし， $\xi_{p \nu,}$ $\xi_{y_{y}{ }^{\prime}}$ をそれらの一般座標とする. $\bar{u}$ は微小で, 次式で 表わされるとする.

$$
\begin{aligned}
& \bar{u}(\bar{r}, t)=\bar{j} u_{y}+\bar{k} u_{x}=\bar{j} \sum_{\nu} \xi_{y \nu} \phi_{y \nu} \\
& \quad+\bar{k} \sum_{\nu} \xi_{p \nu} \phi_{p \nu}
\end{aligned}
$$

$i, \bar{j}, \bar{k}$ はそれぞれ $x, y, z$ 軸方向の単位ベクトル とする。

(iv) 内部流体の機体に対する相対速度を以下に仮 定する. ロケット胴体部の固体部㧍よび流体部をそれ ぞれ， $\tau(B) ， \tau^{\prime}(B)$ とし， $\tau^{\prime}(B)$ 加らスロッシング質量 を除いた部分を $\tau^{\prime}\left(B^{\prime}\right)$ とする， $\bar{t}$ を中線にそった 尾部方向の単位べクトルとすると,

$$
\begin{array}{ll}
\bar{v}_{s}=\dot{\bar{u}} \quad \text { for } & \tau(B) \\
\bar{v}_{f}=\bar{v}_{s}+v_{t} \bar{t} & \text { for } \tau^{\prime}\left(B^{\prime}\right) \\
\bar{t}=-\left(i+\bar{u}^{\prime}\right) & \text { for } \tau(B)
\end{array}
$$

ととに, $\bar{u}^{\prime}=\partial / \partial x(\bar{u}), \dot{u}=\partial^{*} / \partial t(\bar{u})$ とする. v。はタン ク断面で一様で，一定場所では $t$ 亿より不変とする.

つぎに，第 $n$ エンジンの $x y z$ 系に対する位置関係 を第 5 図の如く表わす， $\delta_{p n} ， \delta_{y n}$ はピッチ面括よびヨ 一面に扔けるエンジンふれ角（エンジン支持機構扔よ び油圧アクチュエーター内の流体の弾性変位を含む） で, エンジンの機体に対する固定位置からの変位は, 次の $\bar{\Gamma}_{n}$ なる量を考え，

$$
\bar{\Gamma}_{n}=-\delta_{y n} \bar{j}+\delta_{p n} \bar{k}
$$

$x \bar{\Gamma}_{n}$ (座標原点Oはジンバル点の面内にある)で表わさ
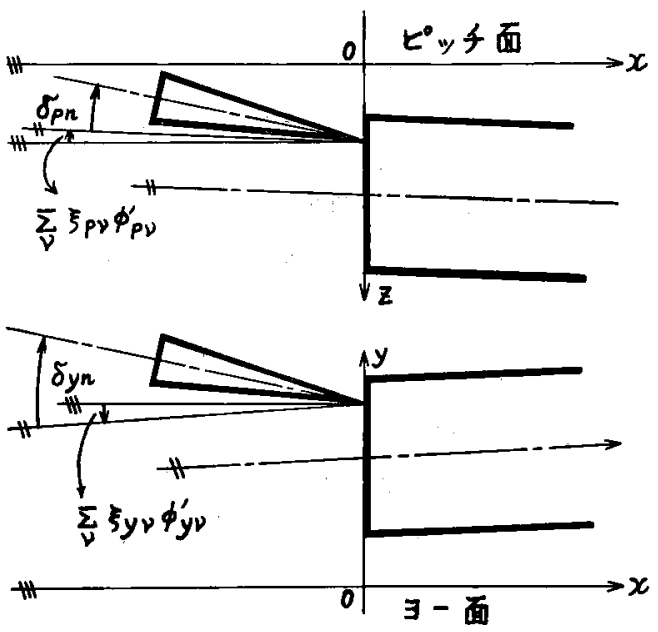

第 5 図 エンジン位置 
れるとする．したがって， $\bar{v}_{f}$ は下記の如く仮定する.

$$
\begin{array}{ll}
\bar{v}_{s}=\dot{\bar{u}}+x \dot{\bar{\Gamma}}_{n} & \text { for } \tau\left(E_{n}\right) \\
\bar{v}_{f}=\bar{v}_{s}+v_{s} \bar{t}_{n} & \text { for } \tau^{\prime}\left(E_{n}\right) \\
\bar{t}_{n}=-\left(\bar{\imath}+\bar{u}^{\prime}+\bar{\Gamma}_{n}\right)
\end{array}
$$

$\bar{t}_{n}$ は第 $n$ エンジンの中心線にそった尾部方向単位べク トルで, $\bar{u}$ は各エンジンについて同一とする， $G_{n}$ を 通って，エンジンの中心軸およびてれに垂直な互に直 交する軸に対する，燃焼ガスも含めたエンジンの慣性 能率を, それぞれ $I_{e x}, I_{e}, I_{e}$ とし，Ieに対して $I_{e x}$ は無視出来るるする.

横スロッシングはタンクの微小変形と, 各個のタン ク長が全長に比して短いととから，剛体タンクのモデ ルを用いる. 第 $k$ スロッシング質量, 固有円振動数打 よび減衰比をそれぞれ， $\mu_{k} ， w_{k} ， \zeta_{k}$ とし， $\bar{S}_{k}$ を横ス ロッシング変位 (第 3 図) として， $\mu_{k}$ の位置ベクト ル $\bar{r}_{k}$ は次式で表わされるとする.

$$
\left.\begin{array}{l}
\bar{r}_{k}=x_{k} \bar{i}+\bar{u}\left(x_{k}\right)+\bar{S}_{k} \\
\bar{S}_{k}=y_{k} \bar{j}+z_{k} \bar{k}
\end{array}\right\}
$$

したがって, $d^{*} / d t\left(\bar{u}\left(x_{k}\right)\right)=\dot{u}\left(x_{k}\right)+\bar{u}^{\prime}\left(x_{k}\right) \dot{x}_{k}$ から, $\mu_{k}$ の機体軸仅対する速度 $\bar{v}_{k}$ は， $\bar{t}\left(x_{k}\right)=\bar{t}\left(x=x_{k}\right)$ 之 し,

$$
\left.\begin{array}{l}
\bar{v}_{k}=\dot{\bar{u}}\left(x_{k}\right)+\dot{\bar{S}}_{k}+v_{t}\left(x_{k}\right) \bar{t}\left(x_{k}\right) \\
v_{k}\left(x_{k}\right)=-\dot{x}_{k}
\end{array}\right\}
$$

（v）重力は機体の場所以よって不変とし, 外力は 空気力と重力のみの場合を考える。

（vi）微小量の仮定. [1] $\mu_{k}, \phi_{p \nu}, \phi_{y \nu}{ }^{\prime}$ 等の時間 に対する偏微分は無視する. [2] $\bar{w}, \bar{\Gamma}_{n}, \bar{S}_{k}, \xi_{p u}$,

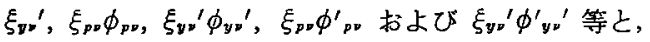
これらの $t$ 亿関する偏微分を微小とする. [3] $\bar{r}_{c}\left(x_{c}\right.$ ， $\left.y_{c}, z_{c}\right)$ の $\dot{x}_{c}, x_{c}$ および $\tau^{\prime}(B) の v_{\iota}$ は微小量とす ろ. [4] $m, m_{p v}, m_{y v}, m_{p y}{ }^{\prime}((55)$ 式)の時間微分老微 小量とする.

重心の運動，回転運動，スロッシング運動㧍よび曲 げ振動式では，上記の微小量の 3 個以上の積を含む項 を削除する．エンジン式では [4] を除いて同様の項を 削除する.

4.2 重心の軍動方程式 ノズル出口のガス流のエ ンジンに対する相対速さを ひ。とし，第 4 図により，

$$
\left.\begin{array}{l}
\int_{\sigma_{e n}} \rho_{f} \bar{r}\left[\left(\bar{v}_{f}-\bar{v}_{s}\right) \cdot \bar{n}_{\tau}{ }^{\prime}\right] d s=-\dot{m}_{n} \bar{r}_{e n} \\
\int_{\sigma_{e n}} \rho_{f} \bar{v}_{f}\left[\left(\bar{v}_{f}-\bar{v}_{s}\right) \cdot \bar{n}_{\tau^{\prime}}\right] d s=-\dot{m}_{n}\left(v_{\varepsilon} \bar{t}_{n}+\dot{\bar{r}}_{e n}\right)
\end{array}\right\}
$$

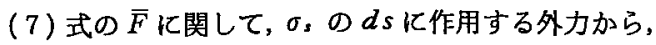
大気静压 $p_{a}$ によるものを差引いた外力を $\bar{n}_{\tau} \cdot \tilde{T}^{\prime} d s$ で表わし， $\bar{r}_{e n}$ のガス代を $p_{e}$ とし， $\sigma_{s}+\sum_{n} \sigma_{i n}$ 作 用する大気静压の合力が0であることを考慮して，

$$
\begin{aligned}
\bar{F} & =\int_{\sigma_{s}} \bar{n}_{\tau} \cdot \tilde{T}^{\prime} d s+\int_{\sigma_{s}}-p_{a} \bar{n}_{\tau} d s \\
& +\sum_{n} \int_{\sigma_{e n}}-p_{a} \bar{n}_{\tau}^{\prime} d s+\sum \int_{n}\left(p_{a}-p_{e}\right) \bar{n}_{\tau}{ }^{\prime} d s \\
& +\int_{\tau+\tau^{\prime}} \bar{R} d m
\end{aligned}
$$

上式の右辺第 2,3 項の和は 0 となり, 第 1 項はいわ ゆる空気力でこれを $\bar{F}_{A}$ で表わし，第 5 項は重力によ る項となり $\bar{F}$ 。で表わし, $\bar{n}_{\tau}{ }^{\prime}=\bar{t}_{n}$ であるから，

$$
\bar{F}=\sum_{n}\left(p_{a}-p_{e}\right) A_{a} \bar{t}_{a}+\bar{F}_{A}+\bar{F}_{0}
$$

(38)，(39)を用い， $\dot{m}=\Sigma \dot{m}_{n}$ を考慮して，(18) 式は

$$
\begin{aligned}
& m\left[\dot{V}_{c}+\bar{w} \times \bar{V}_{c}\right]-2 \sum \dot{m}_{n}\left[\dot{\bar{r}}_{e n}-\dot{\bar{r}}_{c}+\bar{w}\right. \\
& \left.\quad \times\left(\bar{r}_{e n}-\bar{r}_{c}\right)\right]=\bar{F}_{T}+\bar{F}_{A}+\bar{F}_{g}
\end{aligned}
$$

ここに， $\bar{F}_{T}$ は(38)の第2式のうち推力項を右辺に移 して，次式の如くまとめた．Aををノズル出口の断面 皘として,

$$
\left.\begin{array}{l}
T_{c}=-\dot{m}_{n} v_{e}+\left(p_{e}-p_{a}\right) A_{e} \\
\bar{F}_{T}=-\sum_{n} T_{e} \bar{t}_{n}
\end{array}\right\}
$$

$\left(p_{e}-p_{a}\right) A_{\varepsilon}$ はいわゆる王力推力の項である

つぎ $\bar{r}_{c}$ を求める。，いま，機体の曲げ変位がなく $\delta_{\rho n}$ む $\delta_{y n}$ б 0 で，かつスロッシング変位が起てらな いと仮想したとき， $d m$ のOに対する位置ベクトルを $\bar{r}_{R}$ とすると，

$$
\begin{array}{ll}
\bar{r}=\bar{r}_{R}+\bar{u} & \text { for } \tau(B), \tau^{\prime}\left(B^{\prime}\right) \\
\bar{r}_{k}=\bar{r}_{k R}+\bar{u}\left(x_{k}\right)+\bar{S}_{k} & \text { for sloshing mass } \\
\bar{r}=\bar{r}_{R}+\bar{u}+\bar{\Gamma}_{n} x & \text { for } \tau\left(E_{n}\right), \tau^{\prime}\left(E_{n}\right)
\end{array}
$$

また， $t$ で曲げ，エンジンのふれおよびスロッシング が起てらないと仮想したときの重心位置を $\bar{r}_{r}{ }^{0}$ とする と,

$$
\bar{r}_{c}^{0}=\frac{1}{m} \int_{\tau+\tau^{\prime}} \bar{r}_{R} d m
$$

機体の対称性加ら， $\bar{r}_{c}^{0}$ の座標は $\left(x_{c}^{0}, 0,0\right)$ とおけ， (42)，(43)式之，自由一自由棒の固有振動関する次 の慣性力の釣合い式,

$$
\int_{\tau+\tau^{\prime}} \phi_{p \boldsymbol{v}} d m=0, \quad \int_{\tau+\tau^{\prime}} \phi_{y \nu} d m=0
$$

を用いて, エンジンの重心の $x$ 座標を $x_{c n}$ とすれば， (12)，(42)，(43)加ら，

$$
\bar{r}_{c}=\bar{r}_{c}^{0}+\sum_{k}\left(\mu_{k} / m\right) \bar{S}_{k}+\sum_{n}\left(m_{e n} x_{c n} / m\right) \bar{\Gamma}_{n}
$$

$\dot{\vec{r}}_{\varepsilon}, \ddot{\bar{r}}_{c}$ は(45)加ら直接時間微分によって得られる. さらに，後節の回転運動の方程式の導入にも使用す る都合上， $\bar{r}_{e n}$ 亿関する関係式をこてで導いておく。 $\bar{r}_{e n}$ は，曲げ変位がないときの $\bar{r}_{e n}$ を $\bar{r}_{g n}{ }^{0}\left(0, y_{g n^{0}}\right.$, $\left.z_{p \pi}^{0}\right)$ として,

$$
\begin{aligned}
\bar{r}_{e n} & =\bar{r}_{e n}{ }^{0}+x_{e n} \bar{i}+\left\{u_{y}\left(x_{e n}\right)-x_{e n} \delta_{y n}\right\} \bar{j} \\
& +\left\{u_{z}\left(x_{e n}\right)+x_{e n} \delta_{p n}\right] \bar{k}
\end{aligned}
$$


$x_{e n}$ は $\bar{r}_{e n}$ の $x$ 座橴で, 対称配置から次式が仮定出 来る.

$$
\sum_{n} \bar{r}_{a n}^{0}=0 . \quad \sum_{n} y_{0 n}^{0} \delta_{y n}=0, \quad \sum_{n} z_{0 n}^{0} \delta_{p n}=0
$$

なお、ロール制御のためのエンジンふれ角は，ピッチ およびョー制御のためのふれ角に比して微小として， 推力項によるロール・モーメントの場合は除いて, 次 式を仮定する。

$$
\sum_{n} \bar{r}_{b n}{ }^{0} \times \bar{\Gamma}_{n}=0
$$

(45)，(46) および(47)の第 1 式を用い，4.1 の微小 項の処理を行なって $(40) を ~ x y z$ 成分に書下す. この さい重力の加速度 $\bar{g} の x, y, z$ 成分をそれぞれ $g_{x}$, $g_{y}, g_{x}$ とする.

$$
\begin{aligned}
& m\left[\dot{V}_{c x}+w_{y} V_{c z}-w_{z} V_{c y}\right]+2 \dot{m} \dot{x}_{c}^{0} \\
& \quad=F_{T x}+F_{A x}+F_{\theta x} \\
& m\left[\dot{V}_{c y}+w_{z} V_{c x}-w_{x} V_{c x}\right]+2 \dot{m}\left[\dot{y}_{c}-\dot{u}_{y}\left(x_{e n}\right)\right. \\
& \left.\quad+w_{x}\left(x_{c}^{0}-x_{e n}\right)\right]+2 \dot{m}_{n} x_{e n} \sum_{n} \dot{\delta}_{y n} \\
& \quad=F_{T y}+F_{A y}+F_{o y} \\
& m\left[\dot{V}_{c x}+w_{x} V_{c y}-w_{y} V_{c x}\right]+2 \dot{m}\left[\dot{z}_{c}-\dot{u}_{z}\left(x_{e n}\right)\right. \\
& \left.\quad-w_{y}\left(x_{c}^{0}-x_{e n}\right)\right]-2 \dot{m}_{n} x_{e n} \sum_{n} \dot{\delta}_{p n} \\
& \quad=F_{T x}+F_{A z}+F_{v z}
\end{aligned}
$$

$$
\left.\begin{array}{l}
F_{T x}=\sum_{n} T_{e} \\
F_{T_{y}}=T_{e} \sum_{n}\left(u_{y}^{\prime}(0)-\delta_{y n}\right) \\
F_{T z}=T_{e} \sum_{n}\left(u_{z}^{\prime}(0)+\delta_{p n}\right) \\
F_{a x}=m g_{x}, \quad F_{0 y}=m g_{y}, \quad F_{a x}=m g_{x}
\end{array}\right\}
$$

ここに, $u_{y}{ }^{\prime}(0)$ 等はジンバル点 $(x=0)$ に和ける值を 示す. また $\dot{y}_{c}, \dot{z}_{c}$ は(45)で表わされる。

4.3 重心まわりの回転運動方程式（25)でいわゆ る推力項を含むものは左辺の第 9 項で，

$$
\begin{aligned}
& \int_{\sigma_{e n}} \rho_{f}\left(\bar{r}-\bar{r}_{c}\right) \times \bar{v}_{f}\left[\left(\bar{v}_{f}-\bar{v}_{s}\right) \cdot \bar{n}_{\tau}^{\prime}\right] d s \\
& \quad=\dot{m}_{n} v_{e}\left(\bar{r}_{c}-\bar{r}_{e n}\right) \times \bar{t}_{n}+\dot{m}_{n}\left(\bar{r}_{c}-\bar{r}_{e n}\right) \times \dot{r}_{e n}
\end{aligned}
$$

したがって，(41)と同様に推力によるモーメントを， 王力推力の項も含めて， $\bar{M}_{T}^{0}$ であらわす.

$$
\bar{M}_{T}=-\sum_{n} T_{e}\left(\bar{r}_{e n}-\bar{r}_{c}\right) \times \bar{t}_{n}
$$

また，空気力によるモーメントを $\bar{M}_{A}$ とし，(25)の 第 7 項は(38)を用い，末項の皘分は断面中心の位䈯 $\bar{r}_{e n}$ で代表させて，結局(25)式は次式の如く表わされ る.

$$
\begin{aligned}
\tilde{I} \cdot & \dot{\bar{\omega}}+\dot{\tilde{I}} \cdot \bar{w}+\bar{w} \times(\tilde{I} \cdot \varpi)+d^{*} / d t(\bar{L})+\bar{w} \times \bar{L} \\
& -\bar{r}_{c} \times\left[m \dot{\bar{r}}_{c}-2 \sum_{n} \dot{m}_{n}\left(\dot{\bar{r}}_{e n}-\dot{r}_{c}\right)\right]-\bar{w} \\
& \times\left[\bar{r}_{c} \times\left\{m \dot{\bar{r}}_{c}-\sum_{n} \dot{m}_{n} \bar{r}_{e n}\right\}\right]-\sum \dot{m}_{n} \bar{r}_{e n} \\
& \times \dot{\bar{r}}_{e n}-\sum_{n} \dot{m}_{n}\left(\bar{r}_{e n}-\bar{r}_{c}\right) \times\left(\bar{w} \times\left(\bar{r}_{e n}-\bar{r}_{c}\right)\right) \\
& =\bar{M}_{T}+\bar{M}_{A}
\end{aligned}
$$

さて，I を機体曲げ，エンジンのふれおよびスロッ シングが起とらないと仮想したときの $\tilde{I}_{\sigma}^{0}$ で表わす。 このために，(42)，(45) を簡単に, $\bar{r}=\bar{r}_{R}+\bar{d}, \bar{r}_{c}=$

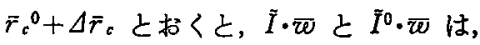

$$
\begin{aligned}
& \tilde{I} \cdot \bar{w}=\int_{\tau+\tau^{\prime}}\left(\bar{r}_{R}+\bar{d}-\bar{r}_{c}^{0}-\Delta \bar{r}_{c}\right) \\
& \quad \times\left\{\bar{w} \times\left(\bar{r}_{R}+\bar{d}-\bar{r}_{c}^{0}-\Delta \bar{r}_{c}\right)\right\} d m \\
& \tilde{I}^{0} \cdot \bar{w}=\int_{\tau+\tau^{\prime}}\left(\bar{r}_{R}-\bar{r}_{c}{ }^{0}\right) \times\left\{\bar{w} \times\left(\bar{r}_{R}-\bar{r}_{c}^{0}\right)\right\} d m
\end{aligned}
$$

で表わされる．機体の対称性と機体曲げ，スロッシン グ変位およびェンジンのふれの仮定から $\Delta \bar{r}_{c}$ の成分 は， $\left(0, y_{c}, z_{c}\right)$ に等しくなる.

さらに, 自由一自由振動の慣性力によるモーメント の验合い式と，一般犋量に関係した定義式および曲げ モードの直交性を示す．以下の関係式

$$
\begin{aligned}
& \int_{\tau+\tau^{\prime}} x \phi_{p \nu} d m=0, \quad \int_{\tau+\tau^{\prime}} x \phi_{y \nu} d m=0 \\
& m_{p \nu}=\int_{\tau+\tau^{\prime}} \phi_{p \nu}^{2} d m, \quad m_{y \nu}=\int_{\tau+\tau^{\prime}} \phi_{y \nu^{2}}{ }^{2} d m \\
& m_{\nu \nu}{ }^{\prime}=\int_{\tau+\tau^{\prime}} \phi_{p \nu} \phi_{y \nu}{ }^{\prime} d m \\
& \int_{\tau+\tau^{\prime}} \phi_{p \nu} \phi_{p \nu}^{\prime} d m=\int_{\tau+\tau^{\prime}} \phi_{\nu \nu} \phi_{\nu \nu} d m=0
\end{aligned}
$$

と，(42)〜 (48)，（55)等を用いて İ を成分に書下す.

$$
\begin{aligned}
& I_{x x}=I_{x x^{0}}+\sum_{\nu} m_{p \nu} \xi_{p \nu}^{2}+\sum_{\nu} m_{y \nu} \xi_{y \nu}{ }^{2}+\sum_{k} \mu_{k}\left[y_{k}^{2}+z_{k}^{2}+2 y_{k} u_{\nu}\left(x_{k}\right)+2 z_{k} u_{x}\left(x_{k}\right)\right]+\sum_{\nu}\left[2 J_{n x} \delta_{p \pi}\right. \\
& \left.-2 J_{n y} \delta_{y n}+I_{c}\left(\delta_{p n}^{2}+\delta_{y n}^{2}\right)\right]-m\left(y_{c}{ }^{2}+z_{c}{ }^{2}\right) \\
& I_{x y}=I_{x y}{ }^{0}-\sum_{k} \mu_{k} x_{k} y_{k}+\sum_{n} I_{e} \delta_{y n}+m x_{c}^{0} y_{c} \\
& I_{x z}=I_{x z}{ }^{0}-\sum_{k} \mu_{k} x_{k} z_{k}-\sum_{n} I_{s} \delta_{p n}+m x_{c}{ }^{0} z_{c} \\
& I_{y y}=I_{v v^{0}}+\sum_{\nu} m_{p y} \xi_{p v^{2}}+\sum_{k} \mu_{k}\left(z_{k}^{2}+2 z_{k} u_{x}\left(x_{k}\right)\right)+\sum_{x}\left[2 J_{n z} \delta_{p n}+I_{\bullet} \delta_{p n}^{2}\right]-m z_{c}^{2} \\
& I_{y z}=I_{y z}{ }^{0}-\sum_{\nu, \nu^{\prime}} m_{\nu \nu} \xi_{p \nu} \xi_{y v^{\prime}}-\sum_{k} \mu_{k}\left(y_{k} z_{k}+z_{k} u_{y}\left(x_{k}\right)+y_{k} u_{z}\left(x_{k}\right)\right)+\sum_{n}\left[\dot{I}_{n z} \delta_{y n}-J_{n y} \delta_{p n}+I_{q} \delta_{p n} \delta_{y n}\right]+m y_{c} z_{c} \\
& I_{z z}=I_{z x}{ }^{0}+\sum_{\nu} m_{y \nu} \xi_{y y}{ }^{2}+\sum_{k} \mu_{k}\left(y_{k}{ }^{2}+2 y_{k} u_{y}\left(x_{k}\right)\right)-\sum_{n}\left[2 J_{n y} \delta_{y n}-I_{\ell} \delta_{y n}{ }^{2}\right]-m y_{c}^{2}
\end{aligned}
$$


つぎに，4.1の $\bar{v}_{s}, \bar{v}_{s}$ を用いて同様に， $\bar{L}$ の成分は，

$$
\begin{aligned}
& L_{x}=\sum_{\nu^{\prime} \nu^{\prime}} m_{\nu \nu^{\prime}}\left(\dot{\xi}_{p \nu} \xi_{\nu \nu^{\prime}}-\xi_{p \nu} \dot{\xi}_{y \nu^{\prime}}\right)+\sum_{k} \mu_{k}\left[y_{k}\left(\dot{z}_{k}+\dot{u}_{z}\left(x_{k}\right)-v_{t}\left(x_{k}\right) u_{z}^{\prime}\left(x_{k}\right)\right)-z_{k}\left(\dot{y}_{k}+\dot{u}_{y}\left(x_{k}\right)\right.\right. \\
& \left.\left.-v_{t}\left(x_{k}\right) u_{y}{ }^{\prime}\left(x_{k}\right)\right)-\dot{y}_{k} u_{x}\left(x_{k}\right)+\dot{z}_{k} u_{y}\left(x_{k}\right)\right]-\sum_{n}\left[\dot{J}_{n y} \delta_{p n}+\dot{J}_{n z} \delta_{y n}-J_{n y} \dot{\delta}_{p n}-J_{n z} \dot{\delta}_{y n}+I_{e}\left(\dot{\delta}_{p n} \delta_{y n}-\delta_{p n} \dot{\delta}_{y n}\right)\right] \\
& +\dot{m} \int_{x_{o n}}^{x_{s}}\left(u_{y} u_{x}{ }^{\prime}-u_{z} u_{y}{ }^{\prime}\right) d x-\dot{m}_{n} x_{\theta n} \sum_{n}\left[\delta_{p x} u_{y}(0)+\delta_{y n} u_{z}(0)\right] \\
& L_{\nu}=-\sum_{k} \mu_{k}\left\{z_{k} v_{s}\left(x_{k}\right)+x_{k} \dot{z}_{k}\right\}-I_{e} \sum_{n} \dot{\delta}_{p n}-\dot{m}\left\{x_{s} u_{k}\left(x_{s}\right)-x_{\varepsilon n} u_{x}\left(x_{e n}\right)\right\}+2 \dot{m} \int_{x_{e n}}^{x_{s}} u_{x} d x \\
& L_{z}=\sum_{k} \mu_{k}\left\{y_{k} v_{t}\left(x_{k}\right)+x_{k} \dot{y}_{k}\right\}-I_{\theta} \sum_{n} \dot{\delta}_{y_{n}}+\dot{m}\left\{x_{s} u_{v}\left(x_{s}\right)-x_{e n} u_{v}\left(x_{\theta n}\right)\right\}-2 \dot{m} \int_{x_{\theta n}}^{x_{k}} u_{y} d x
\end{aligned}
$$

ことに，xsは液面の $x$ 座標で, $J_{n y}, J_{n z}$ は次式とする.

$$
\begin{aligned}
& J_{n y}=m_{e n} x_{c n} u_{y}(0)+I_{e} u_{y}{ }^{\prime}(0) \\
& J_{n z}=m_{e n} x_{c n} u_{x}(0)+I_{e} u_{z}{ }^{\prime}(0)
\end{aligned}
$$

以上の関係式を用い, 4.1 の微小項の処理を行ない，(53)を $x y z$ 成分で表す。

$$
\begin{aligned}
& I_{x x}{ }^{0} \dot{w}_{x}+\left[I_{x y}{ }^{0}-\sum_{k} \mu_{k} y_{k}\left(x_{k}-x_{c}^{0}\right)+\left(I_{c}-m_{c n} x_{c n} x_{c}^{0}\right) \sum_{n} \delta_{y n}\right] \cdot w_{y}+\left[I_{x z}^{0}-\sum_{k} \mu_{k} z_{k}\left(x_{k}-x_{c}^{0}\right)\right. \\
& \left.-\left(I_{e}-m_{e n} x_{e n} x_{c}^{0}\right) \sum_{n} \delta_{p n}\right] w_{z}+\dot{I}_{x x}{ }^{0} w_{x}+\dot{I}_{x y}{ }^{0} w_{y}+\dot{I}_{x x}{ }^{0} w_{x}+\left(I_{x z}{ }^{0}-I_{y y}{ }^{0}\right) w_{y} w_{x}-I_{x y}{ }^{0} w_{x} w_{z}
\end{aligned}
$$

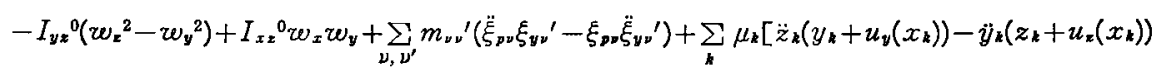

$$
\begin{aligned}
& \left.+y_{k} \ddot{u}_{x}\left(x_{k}\right)-z_{k} \ddot{u}_{y}\left(x_{k}\right)\right]+\sum_{n}\left[J_{n y} \ddot{\delta}_{p n}+J_{n z} \ddot{\delta}_{y n}-\ddot{J}_{n y} \delta_{p n}-\ddot{J}_{n z} \delta_{y n}+I_{c}\left(\delta_{p n} \ddot{\delta}_{y n}-\ddot{\delta}_{p n} \delta_{y n}\right)\right]+m\left(z_{c} \ddot{y}_{c}-y_{c} \ddot{z}_{c}\right) \\
& =M_{T x}+M_{A x} \\
& {\left[I_{x y}{ }^{0}-\sum_{k} \mu_{k} y_{k}\left(x_{k}-x_{c}{ }^{0}\right)+\left(I_{t}-m_{e n} x_{c n} x_{c}{ }^{0}\right) \sum_{n} \delta_{y n}\right] \dot{w}_{x}+I_{y y}{ }^{0} \dot{w}_{y}+I_{y z}{ }^{0} \dot{w}_{x}+\left[\dot{I}_{x y}{ }^{0}-2 \sum_{k} \mu_{k} \dot{y}_{k}\left(x_{k}-x_{c}{ }^{0}\right)\right.} \\
& \left.+2\left(I_{e}-m_{e n} x_{c n} x_{c}^{0}\right) \cdot \Sigma \dot{\delta}_{y n}\right] w_{x}+\left[\dot{I}_{y y}{ }^{0}-\dot{m}_{n} \sum_{n}\left\{\left(z_{v n}{ }^{0}\right)^{2}+\left(x_{e n}-x_{c}\right)^{2}\right\}\right] w_{y}+\dot{I}_{y z}{ }^{0} w_{x}+\left(I_{x x}{ }^{0}\right. \\
& \left.-I_{z z}{ }^{0}\right) w_{z} w_{x}-I_{y x}{ }^{0} w_{y} w_{x}-I_{x z}{ }^{0}\left(w_{x}{ }^{2}-w_{x}{ }^{2}\right)+I_{x y}{ }^{0} w_{y} w_{z}-\sum_{k} \mu_{k}\left(x_{k} \ddot{z}_{k}-z_{k} \ddot{x}_{k}\right)-I_{c} \sum_{n} \ddot{\delta}_{p n} \\
& +m\left(x_{c}{ }_{c}^{0} \ddot{z}_{c}-z_{c} \ddot{x}_{c}^{0}\right)-2 \dot{m}_{n} x_{c}^{0} \sum_{n}\left\{\dot{u}_{z}\left(x_{e n}\right)+x_{e n} \dot{\delta}_{p n}-\dot{z}_{c}\right\}+2 \dot{m} \int_{x_{\theta n}}^{x_{s}} \dot{u}_{z} d x-\dot{m}\left\{x_{s} \dot{u}_{x}\left(x_{s}\right)-x_{e n} \dot{u}_{x}\left(x_{e n}\right)\right\} \\
& =M_{T y}+M_{A y} \\
& {\left[I_{x z}{ }^{0}-\sum_{k} \mu_{k} z_{k}\left(x_{k}-x_{c}^{0}\right)-\left(I_{c}-m_{\theta n} x_{c n} x_{c}^{0}\right) \sum_{n} \delta_{y n}\right] \dot{w}_{x}+I_{y z}{ }^{0} \dot{w}_{y}+I_{z z}{ }^{0} \dot{w}_{z}+\left[\dot{I}_{x z}{ }^{0}-2 \sum_{k} \mu_{k} \dot{z}_{k}\left(x_{k}-x_{c}^{0}\right)\right.} \\
& \left.-2\left(I_{e}-m_{e n} x_{c=} x_{c}^{0}\right) \Sigma \dot{\delta}_{p n}\right] w_{x}+\dot{I}_{y z}{ }^{0} w_{y}+\left[\dot{I}_{z z}{ }^{0}-\dot{m}_{n} \sum_{n}\left\{\left(y_{\theta n}\right)^{2}+\left(x_{e n}-x_{c}^{0}\right)^{2}\right\}\right] w_{x}+\left(I_{v y}{ }^{0}-I_{x x^{0}}\right) w_{x} w_{y} \\
& -I_{x z}{ }^{0} w_{z} w_{y}-I_{z y}{ }^{0}\left(w_{y}^{2}-w_{z}^{2}\right)+I_{y z}^{0} w_{z} w_{x}+\sum_{k} \mu_{k}\left(x_{k} \ddot{y}_{k}-y_{k} \ddot{x}_{k}\right)-I_{\varepsilon} \sum_{n} \ddot{\delta}_{y}-m\left(x_{c}^{0} \ddot{y}_{c}-y_{c} \ddot{\ddot{x}}_{c}^{0}\right) \\
& +2 \dot{m}_{n} x_{c}^{0} \sum_{n}\left\{\dot{u}_{y}\left(x_{e n}\right)-x_{e n} \dot{\delta}_{y n}-\dot{y}_{c}\right\}-2 \dot{m} \int_{x_{e n}}^{x_{s}} \dot{u}_{y} d x+\dot{m}\left\{x_{s} \dot{u}_{y}\left(x_{s}\right)-x_{e n} \dot{u}_{z}\left(x_{\theta n}\right)\right\}=M_{T x}+M_{A z}-
\end{aligned}
$$

$\bar{M}_{T}$ の成分は， $\bar{r}_{e n}=\bar{r}_{g n}{ }^{0}+\bar{u}(0)+x_{e n}\left\{i+\bar{u}^{\prime}(0)+\bar{\Gamma}_{n}\right\}$ を用いて,

$$
\begin{aligned}
& M_{T x}=T \cdot \sum_{n}\left[\left(y_{\theta n}{ }^{0}+u_{v}(0)-y_{c}\right)\left(u_{x}{ }^{\prime}(0)+\delta_{p n}\right)-\left(z_{p n}{ }^{0}+u_{z}(0)-z_{c}\right)\left(u_{y}{ }^{\prime}(0)-\delta_{y n}\right)\right] \\
& M_{T y}=T \cdot \sum_{n}\left[u_{x}(0)+x_{c}{ }^{0}\left(u_{z}^{\prime}(0)+\delta_{p n}\right)-z_{c}\right] \\
& M_{T x}=-T \cdot \sum_{n}\left[u_{v}(0)+x_{c}^{0}\left(u_{y}{ }^{\prime}(0)-\delta_{y n}\right)-y_{c}\right]
\end{aligned}
$$

4.4 スロッシング運動方程式 横スロッシングを 3.3 の如く表わすと， $y, z$ 成分に対して(1)式の右辺は， スプリングの復原力とダシュ・ポットの減衰力および重力の項で表わされる. したがって，第 $k$ スロッシング質 量の $y, z$ 方向の運動方程式は,

$$
\begin{aligned}
\mu_{k}\left[\dot{V}_{k}+\bar{w} \times \bar{V}_{c}+\dot{\bar{w}} \times\left(\bar{r}_{k}-\bar{r}_{c}\right)+\bar{w} \times\left(\bar{w} \times\left(\bar{r}_{k}-\bar{r}_{c}\right)\right)+2 \bar{w} \times\left\{\dot{\bar{u}}\left(x_{k}\right)+\dot{\bar{s}}_{k}+v_{t}\left(x_{k}\right) \bar{t}\left(x_{k}\right)-\dot{\bar{r}}_{c}\right\}+\ddot{\bar{u}}\left(x_{k}\right)\right. \\
\left.\quad+\ddot{\bar{s}}_{k}+d^{*} / d t\left\{v_{t}\left(x_{k}\right) \bar{t}\left(x_{k}\right)\right\}-\overline{\bar{r}}_{c}\right]=-\mu_{k} w_{k}^{2} \bar{s}_{k}-2 \mu_{k} \zeta_{k} w_{k}\left(\bar{s}_{k} /\left|\bar{s}_{k}\right|\right)\left(\bar{s}_{k} \cdot \dot{s}_{k} /\left|\bar{s}_{k}\right|\right)+\mu_{k} \bar{g}
\end{aligned}
$$

とてK, $\left|\bar{s}_{k}\right|$ は $\bar{s}_{k}$ の大きさを表わし，右辺の第 2 項は減衰力が $\bar{s}_{k}$ と直角方向には作用せず， $\left|\bar{s}_{k}\right|$ の変化住対 してのみ作用するとした. (61)を 4.1 の微小項の処理を行ない $y, z$ 成分で表わすと， 


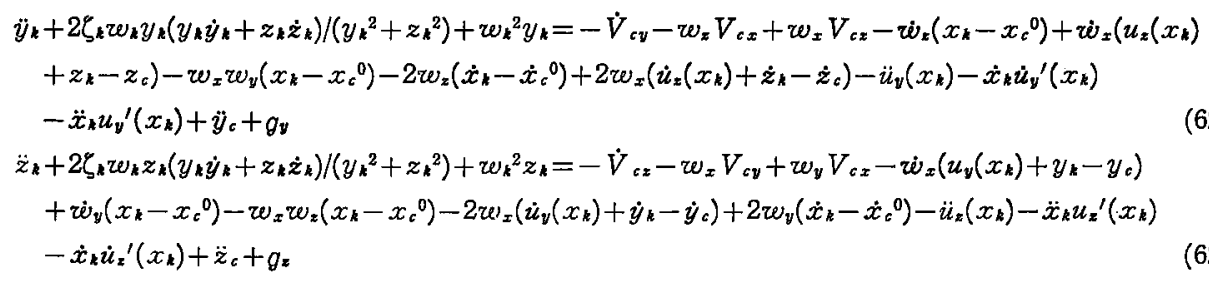

4.5 曲げ振動方程式 (27)式において， $\bar{a}_{a}$ は(42)を用いて(11)より,

$$
\bar{a}_{a}=\dot{\bar{V}}_{c}+\dot{\bar{w}} \times \bar{V}_{c}+\dot{\bar{w}} \times\left(\bar{r}_{R}+\bar{u}-\bar{r}_{c}\right)+\bar{w} \times\left\{\bar{w} \times\left(\bar{r}_{R}+\bar{u}-\bar{r}_{c}\right)\right\}+2 \bar{w} \times\left(\dot{\bar{u}}-\dot{\bar{r}}_{c}\right)+\ddot{u}_{-}-\ddot{r}_{c}
$$

（63）は全機質量素片に適用される，また，(27）式の Qev に寄与するスロッシング変位，エンジンのふれ運動お よび流体の流れによる有効力は，それに対応する慣性力で表わされるとする，いま，(27) 式の記号のうち，固有

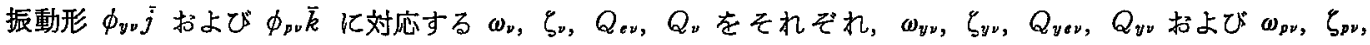

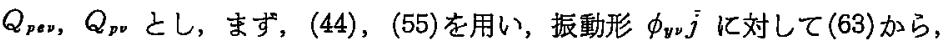

$$
\int_{\tau+\tau^{\prime}} \bar{a}_{a} \cdot\left(\phi_{y \nu} \bar{j}\right) d m=m_{y \nu} \ddot{\xi}_{y \nu}-\left(w_{x}^{2}+w_{z}^{2}\right) m_{y \nu} \xi_{y \nu}-2 w_{x} \sum_{\nu^{\prime}} m_{\nu}{ }^{\prime} \dot{\xi}_{\xi_{\nu}}{ }^{\prime}+\left(w_{y} w_{z}-w_{x}\right) \sum_{\nu^{\prime}} m_{\nu^{\prime}}{ }_{\nu} \xi_{p \nu^{\prime}}
$$

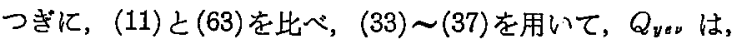

$$
\begin{aligned}
& Q_{v e v}=-\int_{\tau^{\prime}\left(B^{\prime}\right)}\left[2 \bar{w} \times v_{\iota} \bar{t}+d^{*} / d t\left(v_{\iota} \bar{t}\right)\right] \cdot\left(\phi_{y \nu} \bar{j}\right) d m-\sum_{k} \mu_{k}\left[\overline{\bar{w}} \times \bar{s}_{k}+\bar{w} \times\left(\bar{w} \times \bar{s}_{k}\right)+2 \bar{w} \times\left\{\dot{s}_{k}\right.\right. \\
& \left.\left.+v_{\ell}\left(x_{k}\right) \bar{t}\left(x_{k}\right)\right\}+\ddot{\bar{s}}_{k}+d^{*} / d t\left\{v_{t}\left(x_{k}\right) \bar{t}\left(x_{k}\right)\right\}\right] \cdot\left(\phi_{y v}\left(x_{k}\right) \bar{j}\right)-\sum_{n} \int_{\tau\left(E_{n}\right)+\tau^{\prime}\left(E_{n}\right)}\left[\dot{\bar{\omega}} \times \bar{\Gamma}_{n} x-\bar{w} \times\left(\bar{w} \times \bar{\Gamma}_{n} x\right)\right. \\
& \left.+2 \bar{w} \times \dot{\bar{\Gamma}}_{n} x+\ddot{\bar{\Gamma}}_{n} x\right] \cdot\left(\phi_{y \nu} \bar{j}\right) d m-\sum_{n} \int_{\tau^{\prime}\left(E_{n}\right)}\left[2 \bar{w} \times v_{\imath} \bar{t}_{n}+d^{*} / d t\left(v_{\iota} \bar{t}_{n}\right)\right] \cdot\left(\phi_{y v} \bar{j}\right) d m
\end{aligned}
$$

こてで，上式の $Q_{y e v}$ のうち $d^{*} / d t$ の記号を含む項を集めて， $\int_{\tau^{\prime}} \phi_{y v} \bar{j} \cdot \frac{d^{*}}{d t}(v, \bar{t}) d m$ で表わすと， $\dot{\phi}_{y v}$ を無視する 仮定と（付 2.5）を用いて,

$$
\begin{aligned}
& \int_{\tau^{\prime}} \phi_{y \nu} \bar{j} \cdot \frac{d^{*}}{d t}\left(v_{t} \bar{t}\right) d m=\int_{\tau^{\prime}} \frac{d^{*}}{d t}\left[v_{t} \phi_{y \nu}(\bar{j} \cdot \bar{t})\right] d m=\frac{d^{*}}{d t} \int_{\tau^{\prime}}\left[v_{s} \phi_{\nu v}(\bar{j} \cdot \bar{t})\right] d m+\sum_{n} \int_{\sigma_{e n}} \rho_{f} v_{f} \phi_{y \nu}\left(\bar{j} \cdot \bar{t}_{n}\right)\left[\left(\bar{v}_{s}\right.\right. \\
& \left.\left.-\bar{v}_{s}\right) \cdot \bar{n}_{\tau^{\prime}}\right] d s
\end{aligned}
$$

結局, Q Q

$$
\begin{aligned}
& Q_{y e v}=\sum_{k} \mu_{k}\left[-\ddot{y}_{k}+\left(w_{x}^{2}+w_{z}^{2}\right) y_{k}+\left(\dot{w}_{x}-w_{y} w_{z}\right) z_{k}+2 w_{z} \dot{z}_{k}\right] \phi_{y v}\left(x_{k}\right)+\sum_{n}\left[m_{e n} x_{c n} \phi_{y y}(0)+I_{e} \phi_{y v}{ }^{\prime}(0)\right] \\
& \cdot\left[\ddot{\delta}_{y n}-\left(w_{x}^{2}+w_{y}^{2}\right) \delta_{y n}+\left(\dot{w}_{x}-w_{y} w_{z}\right) \delta_{p n}+2 w_{x} \dot{\delta}_{p n}\right]+\dot{m} \int_{x_{\theta n}}^{x_{s}} 2\left(w_{x} u_{z}^{\prime}-w_{x}\right) \phi_{y y} d x \\
& +\sum_{n} \dot{m}_{n} \int_{x_{\varepsilon n}}^{0} 2 w_{x} \delta_{p n} \phi_{y \nu} d x-\frac{d *}{d t}\left[\dot{m} \int_{x_{\varepsilon n}}^{x_{s}} u_{y^{\prime}} \phi_{y^{\prime}} d x-\sum_{n} \dot{m}_{n} \int_{x_{\varepsilon n}}^{0} \delta_{y_{n}} \phi_{y v} d x\right] \\
& -\sum_{n} \dot{m}_{n} v_{\iota} \phi_{v v}\left(x_{e n}\right)\left(u_{y^{\prime}}-\delta_{y n}\right)
\end{aligned}
$$

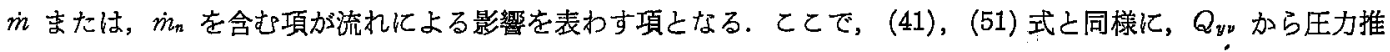
力による一般力と推力による(65)式の末項を合せて $Q_{y} T_{v}$ とすると，

$$
Q_{y T_{v}}=T_{e} \sum_{n}\left(u_{y}{ }^{\prime}(0)-\delta_{y n}\right) \phi_{y v}\left(x_{e n}\right)
$$

また，空気力による一般力を $Q_{v A v}$ とする． $\phi_{p \nu} \bar{k}$ の振動形に対しても同様にして

$$
Q_{p} T_{v}=T \cdot \sum_{n}\left(u_{x}^{\prime}(0)+\delta_{p n}\right) \phi_{p \nu}\left(x_{c n}\right)
$$

結局, 4.1 の微小量の処理を行ない， $\xi_{y v}, \xi_{p v}$ の振動方程式は，次式の如くになる.

$m_{y \nu} \ddot{\xi}_{y \nu}+2 m_{y \nu} \zeta_{y \nu} w_{y \nu} \dot{\xi}_{y \nu}+m_{y \nu} w_{y \nu}{ }^{2} \xi_{y \nu}=\sum_{\nu^{\prime}} m_{\nu}{ }^{\prime}\left(w_{x} \xi_{p \nu^{\prime}}+2 w_{x} \dot{\xi}_{p \nu}{ }^{\prime}\right)+\sum_{k} \mu_{k}\left[-\ddot{y}_{k}+2 w_{x} \dot{z}_{k}+w_{x} z_{k}\right]$

$$
\begin{aligned}
& -\phi_{v v}\left(x_{k}\right)+\left\{m_{e n} x_{c n} \phi_{y v}(0)+I_{c} \phi_{v \nu}{ }^{\prime}(0)\right\} \sum_{n}\left[\ddot{\delta}_{y n}+2 w_{z} \dot{\delta}_{p n}+\dot{w}_{z} \delta_{p n}\right]-\dot{m}_{n}\left[\phi_{y \nu}(0) x_{\theta n}+\phi_{y \nu}{ }^{\prime}(0) x_{e n}{ }^{2} / 2\right] \sum_{n} \dot{\delta}_{y n} \\
& -\dot{m} \int_{x_{\varepsilon n}}^{x_{s}}\left(2 w_{z}+\dot{u}_{\nu}{ }^{\prime}\right) \phi_{v \nu} d x+Q_{v T_{v}}+Q_{v A v}
\end{aligned}
$$

$m_{p \nu} \ddot{\xi}_{p \nu}+2 m_{p \nu} \zeta_{p \nu} w_{p \nu} \dot{\xi}_{p \nu}+m_{p \nu} w_{p \nu}{ }^{2} \xi_{p \nu}=-\sum_{\nu^{\prime}} m_{\nu \nu}{ }^{\prime}\left(\dot{w}_{x} \dot{\xi}_{y \nu^{\prime}}+2 w_{x} \dot{\xi}_{\nu \nu}\right)-\sum_{k}\left[\ddot{z}_{k}+2 w_{x} \dot{y}_{k}+\tilde{w}_{x} y_{k}\right] \phi_{p \nu}\left(x_{k}\right)$ 


$$
\begin{aligned}
& +\left\{m_{e n} x_{c n} \phi_{p \nu}(0)+I_{e} \phi_{p y}^{\prime}(0)\right\} \sum_{n}\left[-\ddot{\delta}_{p n}+2 w_{x} \dot{\delta}_{y n}+\dot{w}_{x} \delta_{y n}\right]+\dot{m}_{n}\left[\phi_{p n}(0) x_{e n}+\phi_{p n}^{\prime}(0) x_{s n}^{2} / 2\right] \sum_{n} \dot{\delta}_{p n} \\
& +\dot{m} \int_{x e n}^{x_{s}}\left(2 w_{y}-\dot{u}_{z}^{\prime}\right) \phi_{p p} d x+Q_{p T \nu}+Q_{p A v}
\end{aligned}
$$

4.6 エンジンの運動方程式 第 $n$ エンジンについて，(35)より $\bar{v}$ ，は次式の如く表わすことが出来る.

$$
\bar{v}_{s}=\dot{\bar{r}}_{a n}+x\left(\dot{\bar{u}}^{\prime}(0)+\dot{\bar{\Gamma}}_{n}\right)
$$

また, エンジンの軸対称性から次式が成立つ.

$$
\int_{\tau^{\prime}\left(E_{n}\right)} v_{t} \bar{r}^{\prime} \times \bar{t}_{n} d m=0
$$

とれらの関係式を用い， $\sigma_{\text {ein }}$ 面の寄与を 0 とおいて，(30)と(31) は次式の如く変形出来る.

$$
\begin{aligned}
& \tilde{I}_{e n} \cdot \overline{\bar{w}}+\dot{\tilde{I}}_{e n} \cdot \bar{w}+\bar{\varpi} \times\left(\tilde{I}_{e n} \cdot \bar{\tau}\right)+m_{e n} \bar{r}_{e n}{ }^{\prime} \times \bar{a}_{o n}+\dot{\bar{L}}_{e n}+\bar{w} \times \bar{L}_{e n}-\dot{m}_{n} \bar{r}_{e n}{ }^{\prime} \times\left(\bar{w} \times \bar{r}_{e n}{ }^{\prime}\right)-\dot{m}_{n} \bar{r}_{e n}{ }^{\prime} \\
& \quad \times\left\{x_{e n}\left(\dot{\bar{u}}^{\prime}(0)+\dot{\bar{\Gamma}}_{n}\right)\right\}=\bar{M}_{e n} \\
& \bar{L}_{e n}=\int_{\tau\left(E_{n}\right)+\tau^{\prime}\left(E_{n}\right)} x \bar{r}^{\prime} \times\left(\dot{u}^{\prime}(0)+\dot{\bar{\Gamma}}_{n}\right) d m
\end{aligned}
$$

まず, (56)の導入と同様にして，機体曲げおよびエンジンふれがないとしたときの $\bar{r}^{\prime}$ を $\bar{r}^{\prime}$ とすると， $\bar{r}^{\prime}=\bar{r}_{R}+x\left(\bar{u}^{\prime}(0)+\bar{\Gamma}_{n}\right)$

したがって, $\tilde{I}_{e n}$ の $x y z$ 成分を後程の微小項の処理を考虑して, 微小項の 1 次の項まで求め, マトリックスの形 で表わすと次のようになる.

$$
\left[\begin{array}{ccc}
0 & -I_{e}\left(u_{y}{ }^{\prime}(0)-\delta_{y n}\right) & -I_{e}\left(u_{x}{ }^{\prime}(0)+\delta_{p n}\right) \\
-I_{e}\left(u_{y}{ }^{\prime}(0)-\delta_{y n}\right) & I_{e} & 0 \\
-I_{e}\left(u_{z}{ }^{\prime}(0)+\delta_{p n}\right) & 0 & I_{\varepsilon}
\end{array}\right]
$$

ただし，4.1 の(iv)により $I_{\text {ex }}$ は無視した.

つぎに, $\vec{L}_{\text {en }}$ の $x y z$ 成分は $(71) よ り$,

$$
\begin{aligned}
& L_{e n x}=I_{e}\left[\left(u_{y}{ }^{\prime}(0)-\delta_{y n}\right)\left(\dot{u}_{z}{ }^{\prime}(0)+\dot{\delta}_{p n}\right)-\left(u_{z}{ }^{\prime}(0)+\delta_{p n}\right) \cdot\left(\dot{u}_{y}{ }^{\prime}(0)-\dot{\delta}_{y n}\right)\right] \\
& L_{\epsilon n y}=-I_{c}\left(\dot{u}_{z}{ }^{\prime}(0)+\dot{\delta}_{p n}\right) \\
& L_{\epsilon n z}=I_{c}\left(\dot{u}_{z}{ }^{\prime}(0)-\dot{\delta}_{y n}\right)
\end{aligned}
$$

さらに, $\delta_{p n}, \delta_{y n}$ の正方向を考慮して $\bar{M}_{e n}$ の $y, z$ 成分を $-M_{a n y},-M_{e n \varepsilon}$ とし, 空気力によるトルクを無 視すると,

$$
\left.\begin{array}{l}
M_{\text {eny }}=M_{\text {enp }}-T_{n f p} \\
M_{\text {enx }}=M_{\text {eny }}-T_{n f y}
\end{array}\right\}
$$

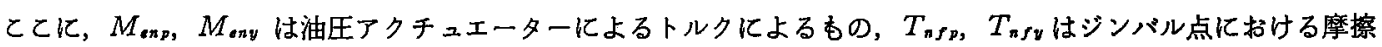
力によるあのである ${ }^{15)}$ ．また機体の運動による慣性力および重力とガス流に゙よるロード・トルクの $y ， z$ 成分を $T_{n L_{p}}, T_{n L y}$ とすると ${ }^{16)} ，(70) の y, z$ 成分は結局次式で表わされる.

$$
\left.\begin{array}{l}
I_{\bullet} \ddot{\delta}_{p n}+T_{n L_{p}}+T_{n f p}=M_{e n p} \\
I_{.} \ddot{\delta}_{y n}+T_{n L_{y}}+T_{n f y}=M_{\text {eny }}
\end{array}\right\}
$$

$\bar{a}_{g n}$ を(11)で表わし，(70)の右辺の重力による項は $m_{e n} \bar{r}_{e n}{ }^{\prime} \times \bar{g}$ となるととを考慮して， $T_{n L_{p}}, T_{n L_{y}}$ を求め， 4.1 の锺小量の処理を行なって次式を得る.

$$
\begin{aligned}
& T_{n L_{p}}=-m_{e n} x_{c n}\left(\delta_{p n}+u_{x}{ }^{\prime}(0)\right)\left[\dot{V}_{c x}+(1 / 2) \dot{V}_{c x}\left(\delta_{p n}+u_{x}{ }^{\prime}(0)\right)+w_{y} V_{c x}-w_{x} V_{c y}+\dot{w}_{y} z_{g n}{ }^{0}-w_{x} y_{\sigma n}{ }^{0}\right. \\
& \left.-\ddot{x}_{\varepsilon}{ }^{0}-g_{x}\right]-2 I_{e} w_{x}\left(\dot{\delta}_{y n}-\dot{u}_{y}{ }^{\prime}(0)\right)-\left(\delta_{y n}-u_{y}{ }^{\prime}(0)\right)\left[I_{\varepsilon} \dot{w}_{x}+(1 / 2) m_{e n} x_{c n} \dot{V}_{c x}\left(\delta_{y n}-u_{y}{ }^{\prime}(0)\right)\right]+I_{e} \ddot{u}_{x}{ }^{\prime}(0) \\
& +m_{e} x_{c n}\left[\dot{w}_{x} u_{y}(0)+2 w_{x} \dot{u}_{y}(0)+\ddot{u}_{z}(0)\right]+m_{e n} x_{c n}\left[\dot{V}_{c z}+w_{x} V_{c y}-w_{y} V_{c x}+\dot{w}_{x}\left(y_{g n}{ }^{0}-y_{c}\right)\right. \\
& \left.+\dot{w}_{y} x_{c}{ }^{0}-2 w_{x} \dot{y}_{c}+2 w_{y} \dot{x}_{c}{ }^{0}-\left(w_{x}{ }^{2}+w_{y}{ }^{2}\right) z_{g n}{ }^{0}-w_{x} w_{x} x_{c}{ }^{0}+w_{y} w_{x} y_{0 n}{ }^{0}-\ddot{z}_{c}-g_{z}\right]-I_{c}\left(\dot{w}_{y}-w_{x} w_{z}\right) \\
& -\dot{m}_{n} x_{e n}^{2}\left[\dot{\delta}_{p n}+\dot{u}_{x}{ }^{\prime}(0)-w_{x}\left(\delta_{y n}-u_{y}{ }^{\prime}(0)\right)-w_{y}\right] \\
& T_{n L_{y}}=-m_{s n} x_{c x}\left(\delta_{y n}-u_{y}{ }^{\prime}(0)\right)\left[\dot{V}_{c x}-(1 / 2) \dot{V}_{c y}\left(\delta_{y n}-u_{y}{ }^{\prime}(0)\right)+w_{y} V_{c z}-w_{z} V_{c y}+\dot{w}_{y} z_{g n}{ }^{0}-\dot{w}_{x} y_{\theta n}{ }^{0}\right. \\
& \left.-\ddot{x}_{c}{ }^{0}-g_{x}\right]+2 I_{e} w_{x}\left(\dot{\delta}_{p n}+\dot{u}_{z}{ }^{\prime}(0)\right)+\left(\delta_{p n}+u_{z}^{\prime}(0)\right)\left[I_{c} \dot{w}_{x}-(1 / 2) m_{e n} x_{c n} \dot{V}_{c y}\left(\delta_{p n}+u_{x}^{\prime}(0)\right)\right]-I_{e} i_{y}{ }^{\prime}(0) \\
& +m_{e n} x_{c n}\left[\dot{w}_{x} u_{z}(0)+2 w_{x} \dot{u}_{z}(0)-\ddot{u}_{v}(0)\right]+m_{e n} x_{c x}\left[-\dot{V}_{c y}+w_{x} V_{c z}-w_{z} V_{c x}+\dot{w}_{x}\left(z_{g n}{ }^{0}-z_{c}\right)\right. \\
& \left.+\dot{w}_{x} x_{c}{ }^{0}-2 w_{x} \dot{z}_{c}+2 w_{z} \dot{x}_{c}^{0}+\left(w_{x}^{2}+w_{x}^{2}\right) y_{0 n^{0}}+w_{x} w_{y} x_{c}{ }^{0}-w_{y} w_{z} z_{g n}{ }^{0}+\ddot{y}_{c}+g_{y}\right]-I_{c}\left(\dot{w}_{s}+w_{x} w_{y}\right) \\
& -\dot{m}_{\pi} x_{e n}{ }^{2}\left[\dot{\delta}_{y n}-\dot{u}_{y}{ }^{\prime}(0)+w_{x}\left(\delta_{p n}+u_{x}{ }^{\prime}(0)\right)-w_{z}\right]
\end{aligned}
$$

$m_{n}$ を含む項がガス流の影響を示す.

したがって，(74)，(75)を用い，油圧アクチュエーターの作動には，例えば線型化の仮定を用いて文献 15) を 
用いて，

$$
\begin{aligned}
& \dddot{\delta}_{p n}+2 \zeta_{p c} w_{p c} \ddot{\delta}_{p n}+w_{p c}{ }^{2} \dot{\delta}_{p n}+K_{p c} w_{p c}{ }^{2} \delta_{p n} \\
& \quad=K_{p c} w_{p c}{ }^{2} \delta_{p c n}-\left(1 / I_{c}\right)\left[\dot{T}_{n L_{p}}+\dot{T}_{n f p}\right. \\
& \left.\quad+2 \zeta_{p c} w_{p c} \cdot\left(T_{n L p}+T_{n f p}\right)\right] \\
& \dddot{\delta}_{y n}+2 \zeta_{v c} w_{y c} \ddot{\delta}_{y n}+w_{v c}{ }^{2} \dot{\delta}_{y n}+K_{y c} w_{y c}{ }^{2} \delta_{y n} \\
& \quad=K_{y c} w_{y c}{ }^{2} \delta_{y c n}-\left(1 / I_{o}\right)\left[\dot{T}_{n L y}+\dot{T}_{n f y}\right. \\
& \left.\quad+2 \zeta_{y c} w_{y c}\left(T_{n L_{y}}+T_{n f y}\right)\right]
\end{aligned}
$$

ここに, $w_{p c}, \zeta_{p c}, K_{p c} ; w_{y c}, \zeta_{y c}, K_{v c}$ はそれぞれ， ピッチ面扔よびヨー面に対するエンジン・サーボコン トローラーの固有振動数之減衰比とサーボ・ゲインで $\delta_{p c n}, \delta_{y \in n}$ はピッチ面㧍よびョ一面のエンジン回転に 対するコマント゚・シグナルである。ロール制御を $\delta_{p n}$ および $\delta_{y n}$ で行なうとすると， $\delta_{p c n} ， \delta_{y c n}$ はそれぞれ ピッチ，ヨ一制御チャンネルの姿勢コマンド・シグナ ルとフィードバック信号以外に，ロール制御のための 姿勢コマンド・シグナルとフィードバック信号で表わ される.

姿勢制御の方程式は，(76)式以外に，フィードバッ ク・シグナル，ポシション・ジャイロ，レート・ジャ イロ，加速度計，迎角計およびエンジン・コマンド・ シグナル等に関する方程式が必要である．とれらにつ いてはここでは言及しない，ただ，次節でてれらのセ ンサーの入力に関係する量を導入する.

4.7 制御センサー取付け位置の角速度，加速度お よひ迎角 ジャイロの機体取付け点の慣性空間に対す る回転角速度は，4.1 の曲林変形を考虑して。

$$
\begin{aligned}
& \bar{w}\left(x_{G R}\right)=w_{x} \bar{i}+\left\{w_{y}-\dot{u}_{x}{ }^{\prime}\left(x_{G R}\right)\right\} \bar{j} \\
& \quad+\left\{w_{z}+\dot{u}_{y}{ }^{\prime}\left(x_{G R}\right)\right\} \bar{k}
\end{aligned}
$$

こてで, $x_{G R}$ はジャイロ取付け点の $x$ 座標で，(32) 式で表わされる機体曲げによる回転角速度の $x$ 成分 は 0 とする。

加速度計取付け点の慣性空間加速度の機体軸成分, $a_{a x}, a_{a y}, a_{a x}$ は，曲げがないときの取付け点の位置 を( $\left.x_{a}, y_{a}, z_{a}\right)$ として，(11)式加ら(42)を用いて,

$$
\begin{aligned}
& a_{a x}=\dot{V}_{c x}+w_{y} V_{c z}-w w_{z} V_{c y}+w_{y}\left[z_{a}+u_{z}\left(x_{a}\right)\right. \\
& \left.-z_{c}\right]-\dot{w}_{z}\left[y_{a}+u_{y}\left(x_{a}\right)-y_{c}\right]+w_{x} w_{y} y_{a} \\
& -\left(w_{y}^{2}+w_{x}^{2}\right) \cdot\left(x_{a}-x_{c}{ }^{0}\right)+w_{x} w_{z} z_{a} \\
& +2 w_{y}\left[\dot{u}_{x}\left(x_{a}\right)-\dot{z}_{c}\right]-2 w_{x}\left[\dot{u}_{y}\left(x_{a}\right)-\dot{y}_{c}\right] \\
& -\ddot{x}_{c}{ }^{0}-g_{x} \\
& a_{a y}=\dot{V}_{c y}+w_{z} V_{c x}-w_{x} V_{c z}+\dot{w}_{x}\left(x_{a}-x_{c}^{0}\right) \\
& -\dot{\boldsymbol{e}}_{x}\left[z_{a}+u_{z}\left(x_{a}\right)-z_{c}\right]+w_{y} w_{x} z_{a}-\left(w_{z}^{2}\right. \\
& \left.+w_{x}{ }^{2}\right) y_{a}+w_{y} w_{x}\left(x_{a}-x_{\varepsilon}{ }^{0}\right)-2 w_{z} \dot{x}_{c}{ }^{0} \\
& -2 w_{x}\left[u_{x}\left(x_{a}\right)-\dot{z}_{c}\right]+\ddot{u}_{y}\left(x_{a}\right)-\ddot{y}_{c}-g_{v} \\
& a_{a z}=\dot{V}_{c z}+w_{x} V_{c y}-w_{y} V_{c x}+w_{x}\left[y_{a}\right. \\
& \left.+u_{y}\left(x_{a}\right)-y_{c}\right]-\dot{v}_{y}\left(x_{a}-x_{c}^{0}\right)+w_{z} w_{x}\left(x_{a}\right. \\
& \left.-x_{c}{ }^{0}\right)-\left(w_{x}^{2}+w_{y}^{2}\right) z_{a}+w_{x} w_{y} y_{a}+2 w_{x} \\
& \cdot\left[u_{y}\left(x_{a}\right)-\dot{y}_{c}\right]+2 w_{y} \dot{x}_{c}{ }^{0}+\ddot{u}_{x}\left(x_{a}\right)-\ddot{z}_{c}-g_{x}
\end{aligned}
$$

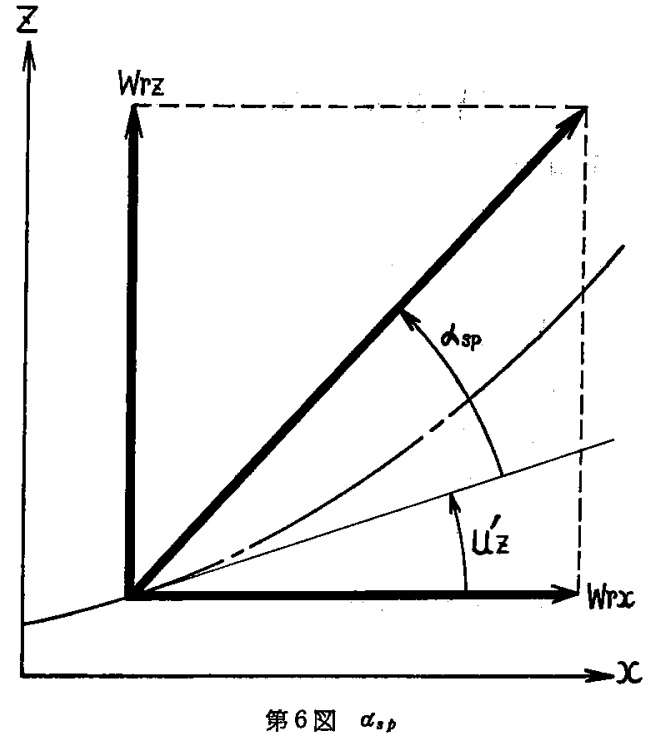

ただし 4.1 の微小項の処理を行なった.

つぎに，迎角計取付け位置におりる局所的な迎角を 求める。いま，慣性軸系を $O_{I}-x_{I} y_{I} z_{I}$ とし（第 1 図)，風の速度は慣性軸系で $\bar{W}_{I}\left(W_{I x}, W_{I y}, W_{I x}\right)$ で 与えられ，重心位置の風速で代表出来るとして，機体 軸系の風の成分 $\bar{W}\left(W_{x}, W_{y}, W_{z}\right)$ は， $x_{I} y_{1} z_{I}$ 系之 $x y z$ 系の座標変換マトリックス $\left[T_{l}\right]$ を用いて，次 式で得られる。

$$
\left\{\begin{array}{l}
W_{x} \\
W_{y} \\
W_{z}
\end{array}\right\}=\left[T_{I}\right]\left\{\begin{array}{l}
W_{I x} \\
W_{I y} \\
W_{I z}
\end{array}\right\}
$$

迎角計は中心軸を含むピッチ面またはヨ一面に取付け られているとし，機体曲げがないときの○に対する位 置ベクトルを $\bar{r}_{\alpha}\left(x_{\alpha}, y_{\alpha}, z_{\alpha}\right)$ とすると，乙の取付け点 の大気化対する相対速度 $\bar{W}_{r}$ は，

$$
\begin{aligned}
\bar{W}_{r} & =\bar{V}_{c}+\bar{w} \times\left\{\bar{r}_{\alpha}+\bar{u}\left(x_{\alpha}\right)-\bar{r}_{c}\right\}+\dot{\bar{u}}\left(x_{\alpha}\right) \\
& -\dot{\bar{r}}_{c}-\bar{W}
\end{aligned}
$$

$\bar{W}_{r}$ の機体軸成分を $W_{r x}, W_{r y}, W_{r z}$ 之し，全迎角の ピッチ面およびヨー面への正斜影をそれぞれ $\alpha_{s p}, \alpha_{s y}$ （第6図）とすると，

$$
\begin{aligned}
& W_{r x}=V_{c x}+w_{y}\left[z_{\alpha}+u_{z}\left(x_{\alpha}\right)-z_{c}\right] \\
& -w_{x}\left[y_{\alpha}+u_{y}\left(x_{\alpha}\right)-y_{c}\right]-\dot{x}_{c}{ }^{0}-W_{x} \\
& W_{r y}=V_{c y}+w_{x}\left(x_{\alpha}-x_{c}{ }^{0}\right)-w_{x}\left[z_{\alpha}\right. \\
& \left.+u_{s}\left(x_{\alpha}\right)-z_{c}\right]+\dot{u}_{y}\left(x_{\alpha}\right)-\dot{y}_{c}-W_{y} \\
& W_{r z}=V_{c z}+w_{x}\left[y_{\alpha}+u_{y}\left(x_{\alpha}\right)-y_{c}\right] \\
& -w_{y}\left(x_{\alpha}-x_{c}{ }^{0}\right)+\dot{u}_{z}\left(x_{\alpha}\right)-\dot{z}_{c}-W_{z} \\
& \alpha_{t p}=\tan ^{-1}\left(W_{r_{z}} / W_{r_{s}}\right)-u_{z^{\prime}}\left(x_{\alpha}\right) \\
& \alpha_{s v}=\tan ^{-1}\left(W_{r v} / W_{r, x}\right)-u_{y}\left(x_{\alpha}\right)
\end{aligned}
$$

\section{5. むすび}

質量が変化しているロケットについて，重心位置の 
変化，機体の曲げ振動。スロッシングおよびェンジン 運動等を考慮して，動力学運動方程式の一般式を，系 らの流出量を用いて簡単で取扱い易い形で尊入した. さらに，推進薬の流れの仮定や assumed モードの設 定などをして，運動方程式におよぼすこれらの諸現象 の影響を詳細に明らかにした．とこでは空気力につい ては言及を略したが，大型の vehicle に通常用いられ る準静的な空気力を用いると，機体の局所的な迎角を (82)式の方法で求めて，空気力を導入出来る．したが って，必要とあれば困難ではあるがシミュレーション が出来る. 特にピッチ面あるいはヨ一面内に限定した 運動などでは比較的簡単であるう.

\section{付 録}

付録 1 発散定理（例えば文献 12）の（i ）に上 りで, $\varepsilon$,

$$
\begin{array}{ll}
\int_{\tau} \nabla \cdot \tilde{T} d \tau=\int_{\tau} \bar{n}_{\tau} \cdot \tilde{T} d s & \text { (付 1.1) } \\
\int_{\tau} \nabla \cdot(\tilde{T} \times \bar{r}) d \tau=\int_{\sigma}\left(\bar{n}_{\tau} \cdot \tilde{T}\right) \times \bar{r} d s & \text { (付 1.2) }
\end{array}
$$

付録 2 連続体の運動をオイラーの方法により場の 量で表わすと，連綕体の実質部分に付随する任意の量 $\bar{A}$ か゚，実質部分の運動ととむに変化する割合を $D / D t$ $(\bar{A})$ で表わすと。すを物質の速度として，直角座標系 で,

$$
D / D t(\bar{A})=\partial / \partial t(\bar{A})+(\bar{v} \cdot \nabla) \bar{A}
$$

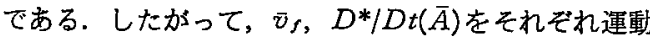
座標系加ら見た物質の速度および実質部分の運動とと あに変化する $\bar{A}$ の割合， $\nabla$ を運動座標系に関する発 散演算子とし，

$$
D^{*} / D t(\bar{A})=\partial^{*} / \partial t(\bar{A})+\left(\bar{v}_{f} \cdot \nabla\right) \bar{A}
$$

を得る. $\partial * / \partial t$ は運動座標軸系の成分についての時間 偏微分である，いま， $\sigma$ をある物質系の運動する物質 粒子が作る閉曲面， $て$ をその内部体積として，文献 13) 上り,

$$
\begin{aligned}
& \frac{D^{*}}{D t} \int_{\tau} \bar{A} d \tau=\int_{\tau} \frac{\partial^{*} \bar{A}}{\partial t} d \tau+\int_{\sigma} \bar{A}\left(\bar{v}_{f} \cdot \bar{n}_{\tau}\right) d s \\
& \quad=\int_{\tau}\left[\frac{\partial^{*} \bar{A}}{\partial t}+\bar{A}\left(\nabla \cdot \bar{v}_{f}\right)+\left(\bar{v}_{f} \cdot \nabla\right) \bar{A}\right] d \tau
\end{aligned}
$$

の関係式が得られる.つぎに，考察する物質粒子が作 る閉曲面とは限らず，運動する任意の閉曲面 $\Sigma$ に围 まれた $T$ 体皘内の物質系の場合にあ，同様( ${ }^{13} ， \bar{v}$, $\bar{n}_{T}$ を任意の閉曲面 $\Sigma$ の $d s$ 部の運動座標系加ら見 た速度および $d s$ 亿垂直な外方向単位べクトルとし $\tau$, 次式を得る.

$$
\frac{D^{*}}{D t} \int_{T} \bar{A} d \tau=\int_{T} \frac{\partial^{*} \bar{A}}{\partial t} d \tau+\int_{\Sigma} \bar{A}\left(\bar{v}_{s} \cdot \bar{n}_{T}\right) d s
$$

さて，以上の関係式を用いて，本文の記号を用い て，ロケットの場合に適用する．固体部については境 界面 $\sigma_{s}$ 之 $\sigma_{s s}$ は固体部粒子が作る面であるから，密 度を $\rho_{s}$ とし連続の式, $\partial^{*} / \partial t\left(\rho_{s}\right)+\nabla \cdot\left(\rho_{s} \bar{v}_{s}\right)=0$ を用い (付 $2 \cdot 2^{\prime}$ ) 加ら，

$$
\begin{aligned}
& \frac{D^{*}}{D t} \int_{\tau} \bar{A} d m=\int_{\tau} \rho_{s}\left[\frac{\partial^{*} \bar{A}}{\partial t}+\left(\bar{v}_{s} \cdot \nabla\right) \bar{A}\right] d \tau \\
& \quad=\int_{\tau} \frac{D^{*} \bar{A}}{D t} d m
\end{aligned}
$$

を得る. (付 2.4)は $\bar{A} d m$ の総和の時間微分は， $D^{*} /$ $D t(\bar{A}) d m$ の総和に等しいととを示し，全く質点邁動 的な取扱いが出来る.つぎ流体部についてはその 境界面のうち $\sigma_{a n}$ は，運動する流体粒子が作る面では なくて，固体部が作るエンジン出口断面であるととを 考えて，(付 2.3) 加ら

$$
\begin{aligned}
& \frac{D^{*}}{D t} \int_{\tau^{\prime}} \bar{A} d m=\int_{\tau^{\prime}} \frac{\partial^{*}\left(\rho_{f} \bar{A}\right)}{\partial t} d \tau \\
& \quad+\int_{\sigma_{s f}} \rho_{f} \bar{A}\left(\bar{v}_{s} \cdot \bar{n}_{\tau}\right) d s+\int_{\Sigma \sigma_{s n}} \rho_{f} \bar{A}\left(\bar{v}_{s} \cdot \bar{n}_{\tau}\right) d s \\
& \quad=\int_{\tau^{\prime}} \frac{\partial^{*}\left(\rho_{f} \bar{A}\right)}{\partial t} d \tau+\int_{\sigma_{s f}+\Sigma \sigma_{e n}} \rho_{f} \bar{A} \\
& \cdot\left(\bar{v}_{f} \cdot \bar{n}_{\tau}\right) d s-\int_{\Sigma \sigma_{e n}} \rho_{f} \bar{A}\left[\left(\bar{v}_{f}-\bar{v}_{s}\right) \cdot \bar{n}_{\tau^{\prime}}\right] d s
\end{aligned}
$$

$\bar{v}_{s}$ は $\sigma_{s n}$ 上の $d s$ の運動座標系から見た速度で，上 式の最初の 2 項の積分を，(付 2.2）（付 2.2'）捄よ び連続の式を用いて変形して，結局次式を得る.

$$
\begin{aligned}
& \frac{D^{*}}{D t} \int_{\tau^{\prime}} \bar{A} d m=\int_{\tau^{\prime}} \frac{D^{*} \bar{A}}{D t} d m \\
& \quad-\sum_{n} \int_{\sigma_{s n}} \rho_{f} \bar{A}\left[\left(\bar{v}_{f}-\bar{v}_{s}\right) \cdot \bar{n}_{\tau^{\prime}}\right] d s
\end{aligned}
$$

上式の右辺の第 2 項の皘分は， $\sigma_{e n}$ 加ら単位時間飞流 出する $\rho_{s} \bar{A} d s$ の総和を表わしている.

付録 3 慣性モーメントテンソル $\tilde{I}$ は対称であり， その $x y z$ 系関する成分はマトリックス表示で。

$$
[I]=\left[\begin{array}{lll}
I_{x x} & I_{x y} & I_{x z} \\
I_{y x} & I_{y y} & I_{y z} \\
I_{x x} & I_{x y} & I_{x x}
\end{array}\right]
$$

である.ただし， $I_{x x}$ 等は次式で定義される.

$$
\begin{aligned}
& I_{x x}=\int_{\tau+\tau^{\prime}}\left[\left(y-y_{c}\right)^{2}+\left(z-z_{c}\right)^{2}\right] d m, \\
& I_{x y}=-\int_{\tau+\tau^{\prime}}\left(x-x_{c}\right)\left(y-y_{c}\right) d m \\
& I_{x x}=-\int_{\tau+\tau^{\prime}}\left(x-x_{c}\right)\left(z-z_{c}\right) d m,
\end{aligned}
$$

付録 4 簡単のため文献 12)の（ii）の記号之，式 
番号をそのまま使用すると，文献の (9-4b) 式は，

$$
\begin{aligned}
\bar{q} & -\bar{q}_{0}-\frac{1}{2}\left(\nabla \times \bar{q}_{0}\right) \times \bar{r} \\
& =-\int_{V} \Gamma(x, y, z ; \xi, \eta, \zeta) \cdot \vec{a} \rho d V \\
& +\int_{V} \Gamma(x, y, ; \xi, \eta, \zeta) \cdot\left(\bar{F}^{D}+\bar{F}^{M}\right) \delta\left(\bar{r}-\bar{r}_{s}\right) d V
\end{aligned}
$$

両辺に $\bar{\phi} \rho$ を乘じて全体積について積分する． $\bar{q}=$ $\sum_{\nu} \bar{\phi}_{\nu} \xi_{\nu}$ 之(9-23)を用いて, 上式の左辺は $M_{\nu} \xi_{\nu}$ とな りまた $\Gamma(x, y, z ; \xi, \eta, \zeta)=\Gamma(\xi, \eta, \zeta ; x, y, z)$ である から，文献の (9-11)を用いて右辺は次のようになる.

$$
\begin{aligned}
& -\int_{V} \bar{a} \rho\left[\int_{V} \Gamma \cdot \bar{\phi}_{\nu} \rho d V\right] d V \\
& +\int_{V}\left(\bar{F}^{D}+\bar{F}^{M}\right) \delta\left(\bar{r}-\bar{r}_{s}\right) \cdot\left[\int_{V} \Gamma \cdot \bar{\phi}_{\nu} \rho d V\right] d V \\
& =-\frac{1}{w_{\nu}^{2}} \int_{V}\left[\bar{\phi}_{\nu}-\bar{\phi}_{\nu 0}-\frac{1}{2}\left(V \times \bar{\phi}_{\nu 0}\right) \times \bar{r}\right] \\
& \quad \cdot \bar{a} \rho d V+\frac{1}{w_{\nu}^{2}} \int_{V} \int_{\nu} \bar{\phi}_{\nu}-\bar{\phi}_{\nu 0}-\frac{1}{2}\left(V \times \bar{\phi}_{\nu 0}\right) \\
& \quad \times \bar{r}] \cdot\left(\bar{F}^{D}+\bar{F}^{M}\right) \cdot \delta\left(\bar{r}-\bar{r}_{s}\right) d V \\
& =\frac{1}{w_{\nu}^{2}}\left[-\int_{V} \rho \bar{a} \cdot \bar{\phi}_{\nu} d V+\int_{S}\left(\bar{F}^{D}+\bar{F}^{M}\right) \cdot \bar{\phi}_{\nu} d S\right]
\end{aligned}
$$

したがって，振動方程式は次式のようになる.

$$
M_{v} w_{\nu}{ }^{2} \xi_{\nu}=-\int_{V} \rho \bar{a} \cdot \bar{\phi}, d V+\int_{S}\left(\bar{F}^{D}+\bar{F}^{M}\right) \cdot \bar{\phi}_{\nu} d S
$$

(付 4.1)

\section{参考文献}

1) Barton, M.V.: The effects of variation of mass on the dynamic stability of jet-propelled missiles, J. Aero. Sci. Vol. 17, No. 4, (1950/4), pp. 197203.
2) 榪津：質量および重心位置が時間とともに変化する口 ケット航空機の運動方程式, 日本航究学会誌, 第 5 巻 第 43 号, (1957), pp. 7-10.

3) Thorpe, J.A. and Hatchinson, R.C. : The dynamics of rocket-powered vehicles, MIT-IL Report 206, (1959).

4) Thomson, W.T. : Introduction to space dynamics, John Wiley \& Sons, Inc., New York, (1963), pp. 230-235.

5) Thomson, W.T. and Reiter, G.S.: Jet damping of a solid rocket: Theory and flight results, AIAA J., Vol. 3, No. 3, (1965), pp. 413-417.

6) Thomson, T.W. : Equations of motion for the variable mass system, AIAA., Vol. 4, (1966), pp, 766-768.

7) JAMEs, R. L.: A three dimensional trajectory simulation using six-degree-of-freedom with arbitrary winds, NASA TND-641, (1961).

8) HARris, J.R. : A Trajectory simulation applicable to stability and control studies of Large multiengine vehicles, NASA TND-1838, (1963).

9) Lester, H.C, and Collins, D.F.: Determination of loads on a flexible launch vehicle, NASA TND-2590, (1965).

10) Greensite, A.L. : Analysis and design of space vehicle flight control systems, Vol II-Trajectory equations, NASA CR-821, (1967).

11) B. BLknap, S.B.: A general transport rule for variable mass dynamics, AIAA J., Vol. 10, No. 9, (1972), pp. 1137-1138.

12) Bispinghoff, R. L. and Ashley, H. : Principles of aeroelasticity, John Wiley \& Sons, Ins., New York, (1962), (i) p. 22, (ii) p. 187, pp. 451-457.

13) ERINGEN, A.C.: Mechanics of continua, John Wiley \& Sons, Inc., New York, (1967), p. 75.

14) Arramson, H. N.: The dynamic behavior of liquid in moving containers, NASA SP-106, (1966), pp. 199-223.

15) Cooztre, J.G.R.: Analysis and design of space vehicle flight control systems, Vol. XI-Component dynamics, NASA CR-830, p. 68 , p. 70.
(640 ページから続く)

フランジのスプライスが重なってくる.

部品全長は $3,193 \mathrm{~mm}$ で, 材質は高力アルミニウム 合金 7075 の板厚 $12.5 \mathrm{~mm}$ の厚板である. 加工法は まず粗切削を行なった後ストレッチ・フォーミング 法でコード方向のねじれをふくむコンターをつけ，ケ ミカル・ミーリングで助骨部を溶削する．つぎに桁部 とコードのあたる中央背骨部をならいフライス盤で筋 彫りして仕上げ, 最後にアーム・ルーターで外形をト リムする.

この部品は複雑な面を多く持っている点と，多数の 部品に挾まれて組立てられるため，各部の寸度が正確 でなければなら点に特徴があり，また加工の面でも 板金技術のストレッチ，ケミミル法と機械加工を組合 わせている点に特徴がある.

第 2 図 2 頭フライスによる一体化部品の切削 最近
の削り出し一体化構造部品の切削加工は, 部品の大型 化・複雑化のため，切削時間が長くなる傾向にある. また，超高抗張力鋼・テタニウム合金などの難削材の 場合は，さらにこの傾向が助長される，この傾向に対 する対策として，工作機械の主軸頭数を多くし，数個 の同じ部品を同時に切削することによって，設備投資 や，加工工数の低減が計られている.

第 2 図の加工中の部品は，大型輸送機のフラップの レールで長さ約 $2.5 \mathrm{~m}$ 材質はクロム・モリブデン鋼 でロックウェル硬度 RC 45 に熱処理硬化してある.

工作機械は 2 頭の数値制御フライス帮で加工精度は $\pm 0.05 \mathrm{~mm}$ である.

このような部品切削の技術的問題点は，熱好理など による残留応力によって切削加工中に雪み加発生する 点や，切粉がカッターに巻き込まれカッターを損傷す ること,および 2 個のカッターの精度管理などである。 